\title{
Oncogenic protein interfaces: small molecules, big challenges
}

\author{
Tracy L. Nero' ${ }^{1}$ Craig J. Morton', Jessica K. Holien', Jerome Wielens ${ }^{1,2}$ \\ and Michael W. Parker ${ }^{1,3}$
}

\begin{abstract}
Historically, targeting protein-protein interactions with small molecules was not thought possible because the corresponding interfaces were considered mostly flat and featureless and therefore 'undruggable'. Instead, such interactions were targeted with larger molecules, such as peptides and antibodies. However, the past decade has seen encouraging breakthroughs through the refinement of existing techniques and the development of new ones, together with the identification and exploitation of unexpected aspects of protein-protein interaction surfaces. In this Review, we describe some of the latest techniques to discover modulators of protein-protein interactions and how current drug discovery approaches have been adapted to successfully target these interfaces.
\end{abstract}

High-throughput chemical screening

(HTS). A systematic way to measure the modulation of an interaction or a biological function against a given protein target by a large number of individual compounds.

${ }^{1}$ Australian Cancer Research Foundation Rational Drug Discovery Centre and Biota Structural Biology Laboratory, St. Vincent's Institute of Medical Research, 9 Princes Street, Fitzroy, Victoria 3065, Australia ${ }^{2}$ Department of Medicine, University of Melbourne, 41 Victoria Parade, Fitzroy, Victoria 3065, Australia. ${ }^{3}$ Department of Biochemistry and Molecular Biology, Bio21 Molecular Science and Biotechnology Institute, University of Melbourne, Parkville, Victoria 3052, Australia.

Correspondence to M.W.P. e-mail:mparker@svi.edu.au doi:10.1038/nrc3690 Published online 13 March 2014
Protein-protein interactions (PPIs) form the molecular bases of many physiological processes in health and disease. In cancer, PPIs can have important regulatory roles; for example, in the cell division cycle or in cell signalling. The specificity and affinity of these interactions are critically important - changes in them can lead to cellular malfunctions, such as the uncontrolled cell growth that typifies cancer. Thus, it is not surprising that modulators of PPIs, whether as biological agents (such as antibodies) or as small-molecule synthetic compounds, are urgently being sought and developed by the pharmaceutical industry to treat an unmet medical need.

This interest in PPIs as drug targets has historically been tempered by the pervasive view that finding molecules, particularly small synthetic molecules (those $<500 \mathrm{Da}$ ), that will modulate PPIs is irredeemably hampered by the large, flat, featureless areas of protein surfaces that form the interface - an interface that is thought to be 'undruggable' (REFS 1-4). This has often been in spite of compelling evidence from molecular, cellular and animal studies that such targets have an excellent potential for drug development. Nevertheless, major inroads into discovering such molecules have been made in recent years, with more than 12 smallmolecule PPI modulators currently in clinical development (TABLE 1) and sales worldwide predicted to be in excess of US\$800 million within 5 years ${ }^{5}$.

As with other areas of drug discovery, a major challenge is to identify and validate physiologically relevant PPIs as cancer-related targets; this task is particularly challenging for many PPIs, as they can be transient in nature.
The most common tools for identifying PPIs have been genetic approaches, such as yeast two-hybrid, synthetic lethal, systematic RNA interference and co-evolution analyses; cell biology approaches, including the localization of proteins with fluorescent markers; proteomic approaches, such as affinity purification and mass spectrometry (MS) of complexes and protein arrays; and direct protein co-purification and immunoprecipitation. The past couple of years have also seen the development of highly sophisticated approaches to genome-wide prediction of interacting proteins, including studies that have identified more than 300,000 potential interaction pairs encoded in the human genome ${ }^{6}$. Of particular relevance to cancer is the genome-wide profiling of tumour samples by initiatives such as The Cancer Genome Atlas and the International Cancer Genome Consortium.

Validating the physiological relevance of a PPI to cancer facilitates the initiation of a drug discovery programme. The pathways in a typical drug discovery programme are outlined in FIG. 1; the nature of the protein target and the available resources will dictate which pathways are followed. FIGURE 2a illustrates how different approaches are being applied to a single protein target in the hunt for PPI modulators. As well as traditional high-throughput chemical screening (HTS), structure-based discovery approaches are now common. In addition to the challenges described above, these approaches face another challenge that is specific to PPIs. There is a wide gulf between the number of experimentally determined protein structures and the 


\section{Key points}

- More than 300,000 interaction pairs have already been identified in the human genome; therefore, modulating protein-protein interactions (PPIs) has a huge potential for therapeutic intervention in cancer.

- The refinement of existing bioassay techniques and the development of new ones, together with the identification and exploitation of unexpected aspects of PPI surfaces has led to more than 12 small-molecule PPI modulators making it to the clinic in recent years.

- Advances in the structural and biological understanding of the PPI to be modulated are shaping the compound libraries being used for PPI screening; for example, three-dimensional shape diversity, chirality and pharmacokinetic properties are now included in the library design.

- Improvements in data handling, robotics and miniaturization of assay technology has allowed increasing numbers of compounds to be evaluated against a given protein target using high-throughput screening (HTS) methods.

- The availability of cheap computational power has led to the routine use of virtual screening in the discovery of small-molecule PPI modulators, either as a stand-alone method to identify potential hits or as a prelude to HTS. Active compounds that are identified from the virtual screening process then undergo a traditional medicinal chemistry optimization process.

- Sensitive methods such as protein-based or ligand-based NMR, X-ray diffraction and surface plasmon resonance allow the use of fragments of low affinity and specificity to be used for the discovery and development of small-molecule PPI modulators.

- The therapeutic class of biologicals, which includes antibodies, peptides and aptamers, generally has high target specificity and potency. Biologicals are particularly useful for PPI modulation, as they can be readily tuned to bind to a large variety of protein surfaces and are often used as a starting point for PPI drug discovery programmes.

Small-angle X-ray scattering A technique that is used to measure the average size and shape of a protein or a protein complex in solution, in the resolution range of $1-25 \mathrm{~nm}$

Orthosteric PPI modulators A site on the protein-protein interaction surface of one of

the protein partners is targeted by an orthosteric PPI

modulator to alter the interaction, usually by preventing the interaction occurring but in some cases by stabilizing the protein complex. number of proteins that have been implicated in human cancers. This is especially true for protein-protein complexes, which represent less than $0.5 \%$ of the structures deposited in the Protein Data Bank ${ }^{6}$. Thus, computational methods, such as protein docking and homology modelling, that are combined with low-resolution experimental approaches (for example, mutagenesis, chemical crosslinking, hydrogen-deuterium exchange, cryo-electron microscopy, fluorescence spectroscopy and small-angle X-ray scattering) have proved to be useful when the structure of the protein complex of interest is not available.

Therapeutic proteins, such as monoclonal antibodies, which target PPIs that are accessible to the extracellular environment, have proved to be extremely successful in the clinic during the past decade (see Supplementary information S1 (table)). However, biologicals (protein-based drugs, peptides, aptamers and other macromolecules; see Supplementary information S2, S3 (tables)) can be expensive and are rarely cell-permeable or orally available. Hence, the typically lower cost of treatment, ease of use and potential to target intracellular PPIs all drive the current substantial interest in the discovery of small synthetic molecule PPI modulators. Several recent reviews on the topic of PPI modulators are available, and these cover areas such as PPI characterization ${ }^{7}$, the use of specific techniques for PPI drug discovery ${ }^{3,8-11}$ and a comparison of the properties of PPI modulators with enzyme inhibitors ${ }^{12}$. In this Review, we highlight recent technological advances in the field, with a particular emphasis on early stage drug discovery - chiefly focused on small molecules, including peptides and aptamers - and we illustrate these with examples of cancer-related PPIs being targeted for therapeutic intervention.

\section{PPIs and protein-protein interfaces}

The term 'protein-protein interface' potentially covers an enormous range of different, physiologically relevant interaction surfaces within biological systems. Interactions between monomers in multimeric proteins, interactions in multi-molecular complexes, recognition of activation signals (such as phosphorylation, proteolysis and receptor-hormone interactions) and many antibody-antigen binding events all involve the formation of protein-protein interfaces with extremely diverse affinities and specificities. The huge diversity of PPIs and corresponding protein-protein interfaces means that it is difficult to generalize about the characteristics of such sites. For most people, the term protein-protein interface brings to mind the large surfaces that are present in globular protein complexes, receptor-hormone complexes and antibody-protein interactions, much like the interleukin-2 (IL-2)interleukin-2 receptor subunit- $\alpha$ (IL-2R $\alpha$ ) interface shown in FIG. $2 b$, and the term ignores those surfaces that more closely resemble a classic protein-small-molecule interface, such as the BCL- $\mathrm{X}_{\mathrm{L}}-\mathrm{BAX} \mathrm{BH} 3$ domain interface that is shown in FIG. 2a. This perception is unfortunate, as many key interactions between proteins are transient events that occur through small interfaces that are in some ways more akin to ligand binding sites. Some of the aspects of interfaces in PPIs and the characteristics that facilitate their targeting during drug discovery are outlined in BOX 1.

Although many protein interfaces lack clearly defined pockets, there is a bias in the positioning of physiological ligand binding sites to be close to or even directly associated with the edge of protein-protein contacts ${ }^{13}$. Inspection of a set of 1,611 protein-protein complexes showed that in those protein complexes with a known ligand binding site about one-half of the sites contained amino acids from both proteins. In most cases, binding pockets were found to be within $6 \AA$ of the protein-protein interface. Therefore, these sites have the potential to provide convenient anchor points for the development of compounds that interfere with the protein-protein interface.

All modulators of protein activity, including PPI modulators, fall into two broad functional classes. Orthosteric PPI modulators directly target the interacting interface of one of the protein partners and, in doing so, they alter the interaction, usually by preventing the interaction occurring but in some cases by stabilizing the protein complex. By contrast, allosteric PPI modulators bind at a site that is distinct from the interaction interface and, in doing so, they modify their protein target - normally by inducing a conformational change that subsequently alters the formation of the PPI. Thus, approaches to target both types of modulation should be considered. Unless otherwise specified, the smallmolecule examples that are discussed in this Review are orthosteric PPI modulators. 
REVIEWS

Table 1 | Recent examples of small-molecule modulators of cancer-related protein-protein interactions in the clinic

\begin{tabular}{|c|c|c|c|c|c|c|}
\hline Cancer type & Target PPI & Chemical structure & $\begin{array}{l}\text { Molecular } \\
\text { mass } \\
\text { (cLogP) }\end{array}$ & $\begin{array}{l}\text { Generic } \\
\text { name } \\
\text { (type of } \\
\text { modulator) }\end{array}$ & $\begin{array}{l}\text { Clinical } \\
\text { phase }\end{array}$ & Refs \\
\hline $\begin{array}{l}\text { AML, CML, } \\
\text { pancreas and } \\
\text { solid tumours }\end{array}$ & $\begin{array}{l}\beta \text {-catenin- } \\
\text { CREB- } \\
\text { binding } \\
\text { protein }\end{array}$ & & $\begin{array}{l}549 \mathrm{Da} \\
(6.1)\end{array}$ & $\begin{array}{l}\text { PRI-724 or } \\
\text { ICG-001 } \\
\text { (orthosteric } \\
\text { inhibitor) }\end{array}$ & Phase I/II & $\begin{array}{r}143 \\
144\end{array}$ \\
\hline $\begin{array}{l}\text { AML, lymphoma } \\
\text { and solid tumours }\end{array}$ & $\begin{array}{l}\text { IAP family- } \\
\text { SMAC }\end{array}$ & & $\begin{array}{l}807 \mathrm{Da} \\
(2.8)\end{array}$ & $\begin{array}{l}\text { TL32711 } \\
\text { (orthosteric } \\
\text { inhibitor) }\end{array}$ & Phase I/II & 145 \\
\hline Breast & $\begin{array}{l}\text { Tubulin- } \alpha- \\
\text { tubulin- } \beta\end{array}$ & $\mathrm{H}_{2} \mathrm{~N}$ & $\begin{array}{l}730 \mathrm{Da} \\
(1.2) \text { free } \\
\text { base; } \\
826 \mathrm{Da}, \\
\text { mesylate } \\
\text { salt }\end{array}$ & $\begin{array}{l}\text { Eribulin } \\
\text { mesylate or } \\
\text { E7389 } \\
\text { (allosteric } \\
\text { inhibitor) }\end{array}$ & $\begin{array}{l}\text { In the } \\
\text { clinic }\end{array}$ & $\begin{array}{r}148 \\
149\end{array}$ \\
\hline Breast & $\begin{array}{l}\text { Tubulin- } \alpha- \\
\text { tubulin- } \beta\end{array}$ & & $\begin{array}{l}507 \mathrm{Da} \\
(3.1)\end{array}$ & $\begin{array}{l}\text { Ixabepilone } \\
\text { (allosteric } \\
\text { stabiliser) }\end{array}$ & $\begin{array}{l}\text { In the } \\
\text { clinic }\end{array}$ & $\begin{array}{l}150 \\
151\end{array}$ \\
\hline
\end{tabular}




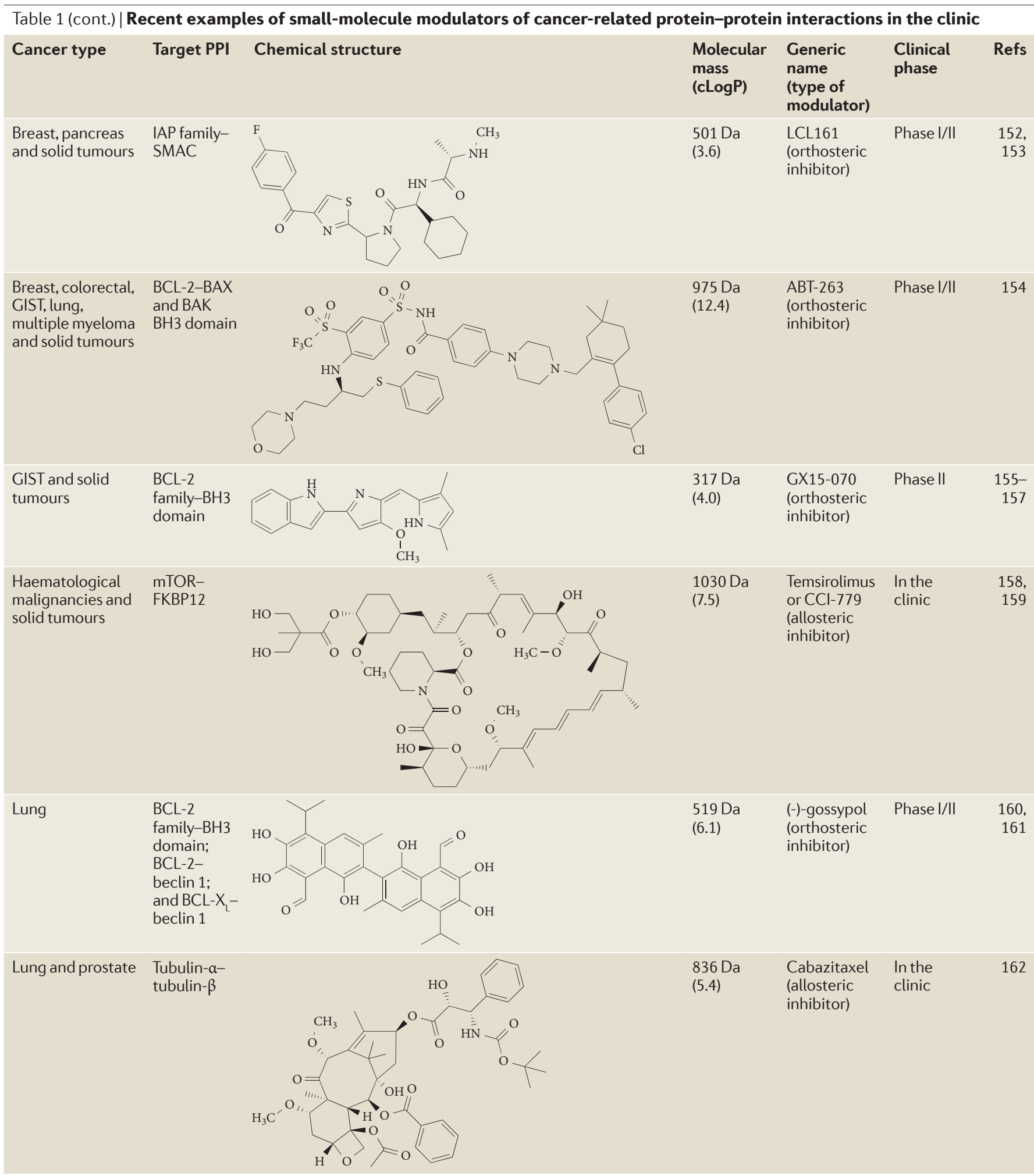

AML, acute myelogenous leukaemia; cLogP, calculated LogP; CML, chronic myelogenous leukaemia; GIST, gastrointestinal stromal tumour; IAP, inhibitor of apoptosis; PPI, protein-protein interaction; SMAC, second mitochondria-derived activator of caspases.

\section{Methods of monitoring PPI disruption}

Monitoring the effect of PPI modulators can require quite different experimental approaches, depending on the specific PPI. Clearly, the most important aspect of PPI modulation is whether there is a physiologically relevant effect on the system that is being targeted. Although the direct binding of compound to protein or the impact of compounds on the stability of the protein complex are important, an assay of biological activity is ultimately going to be the defining result: 
Isothermal calorimetry

(ITC). A way of directly measuring the heat that is released or absorbed in a sample upon complex formation (that is, proteinprotein or protein-ligand complex formation).

Surface plasmon resonance (SPR). A technique that measures the interaction of molecules through changes in the refractive index that occur when ligands that are bound to a surface interact with another molecule in solution.

Microscale thermophoresis A technique that measures changes in the mobility of a protein in solution along an induced temperature gradient upon ligand binding or complex formation.

Fluorescence resonance energy transfer

(FRET; also known as Förster resonance energy transfer). An assay technique that is used to measure interactions such as protein-protein interactions. A measurable signal is generated when an acceptor chromophore and a donor chromophore that are attached to two components of a system are stabilized in close proximity and are able to transfer excitation energy from the acceptor to the donor.

Amplified luminescent proximity homogeneous assay screen

(AlphaScreen; PerkinElmer). A non-radioactive assay that measures the interactions between two components attached to luminescent donor and acceptor beads. A measurable signal is generated when an acceptor bead and a donor bead are held in close proximity through the attached molecules.

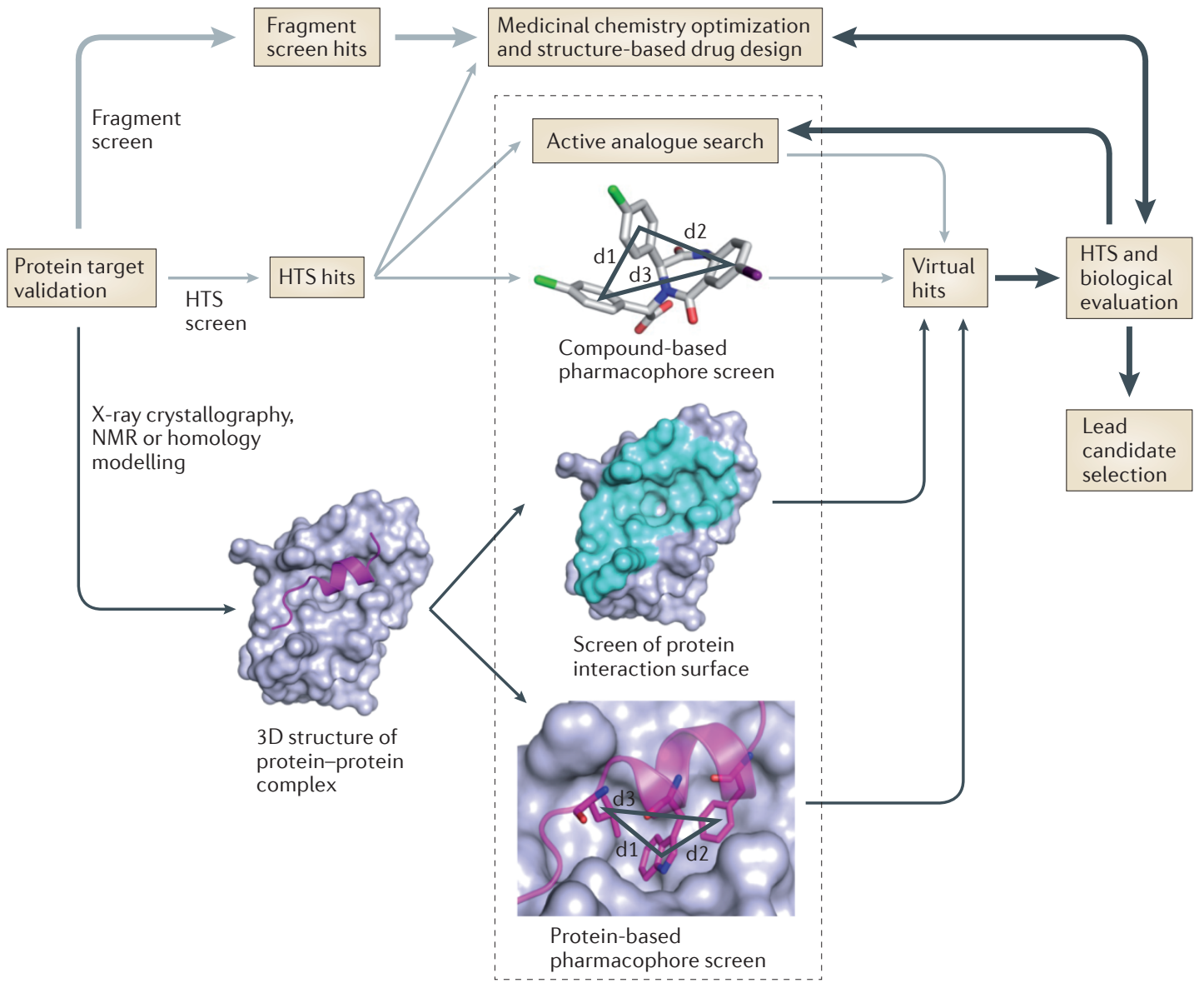

Figure 1 | The drug discovery process and protein-protein interactions. Once the protein target has been validated, screening of fragment or small-molecule compound libraries is undertaken to identify 'hits' that bind to the protein and modulate the protein-protein interaction. The virtual screening (VS) methodologies are enclosed in the dashed box. It is common for combinations of fragment screening, high-throughput screening (HTS) and VS to be done in parallel, with the data being fed into the structure-based drug design and medicinal chemistry optimization process. 3D, three-dimensional.

does the PPI modulator change the biology? However, bioassays have the disadvantage that they are often relatively insensitive: they need compounds with low micromolar activity or higher before an effect on the assay is observed. Although this is suitable for later stage development, identifying initial 'hit' compounds of relatively low potency requires more sensitive techniques than the typical bioassay can provide.

Screening for PPI modulators is mostly carried out in the same way as screening for any inhibitor of protein function. Various biophysical techniques can be used to directly measure the interaction between a drug and the target protein, such as MS, NMR, isothermal calorimetry (ITC), surface plasmon resonance (SPR), microscale thermophoresis, fluorescence anisotropy or X-ray crystallography. Examples of these approaches being used to characterize the effects of molecules that regulate cancer-related PPIs have been published ${ }^{8,14-16}$, and some are described below: in many cases, identical PPI targets were explored using completely different techniques by independent research groups.

\section{HTS approaches to modulate PPIs}

HTS is a well-established strategy that has been used for several decades by industry and, more recently, by academic groups to identify new small molecules that can modulate the activity of a protein target ${ }^{14,17,18}$. Continued improvements in data handling, robotics and miniaturization of assay technology has allowed increasing numbers of compounds from in-house libraries and commercial suppliers to be tested efficiently, reliably and with a relatively low cost per assay ${ }^{14,17}$. Despite this impressive history in classical drug discovery, HTS has had mixed results in identifying new leads for modulating PPIs ${ }^{1}$, partly owing to the difficulties with developing suitable high-throughput assays to assess the PPI to be modulated in vitro. Despite the potential of robust assay methods such as fluorescence resonance energy transfer (FRET; also known as Förster resonance energy transfer), amplified luminescent proximity homogeneous assay screen (AlphaScreen; PerkinElmer), enzyme-linked immunosorbent assay (ELISA) and fluorescence polarization (FP), which involve a measurable change in fluorescence or absorbance upon formation of a PPI, or the use of highly 

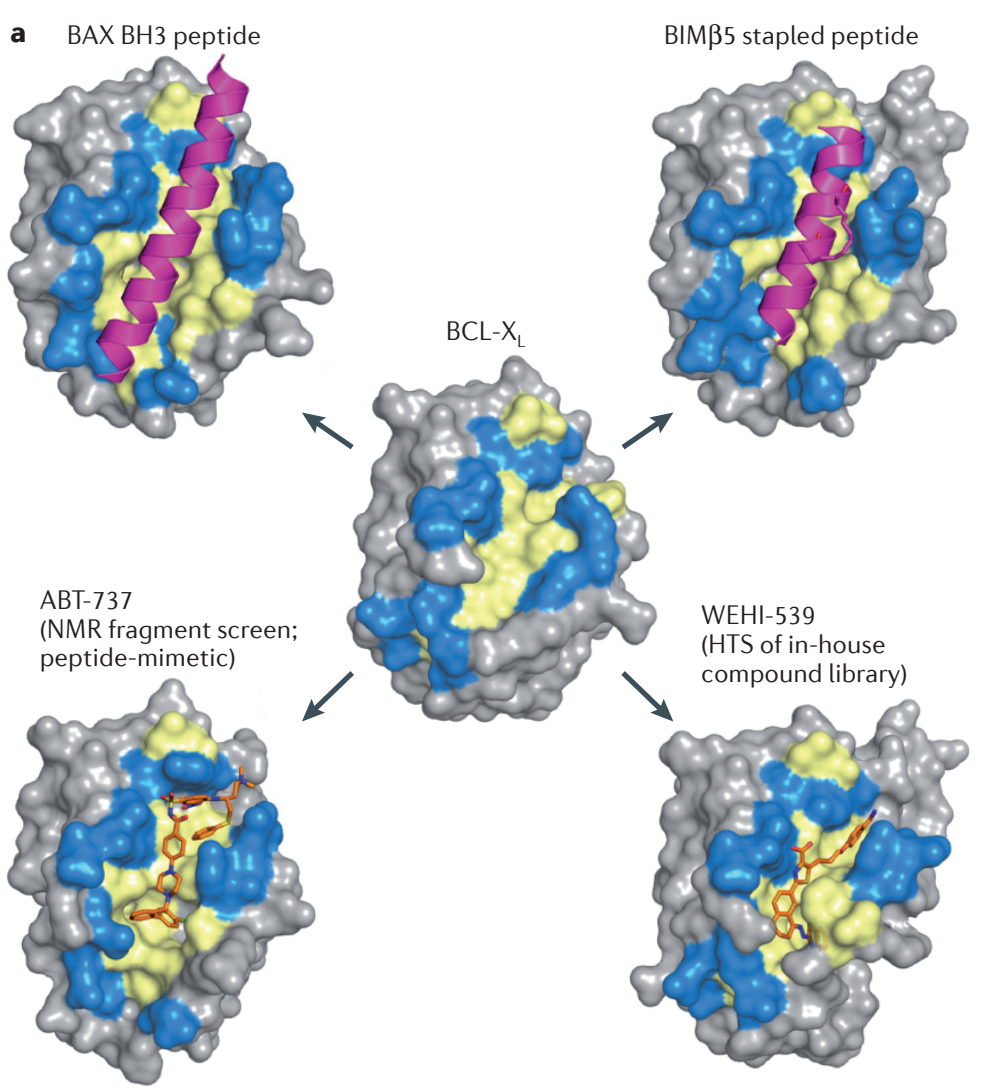

b

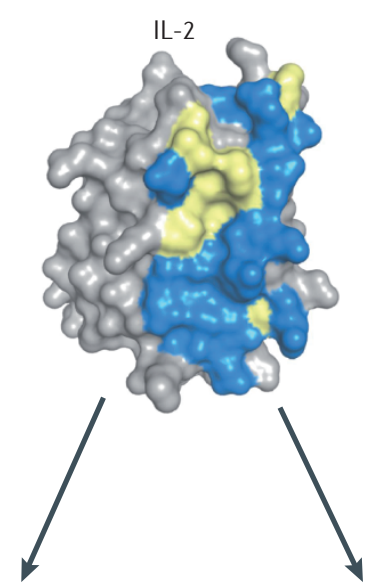

WEHI-539

(HTS of in-house compound library)
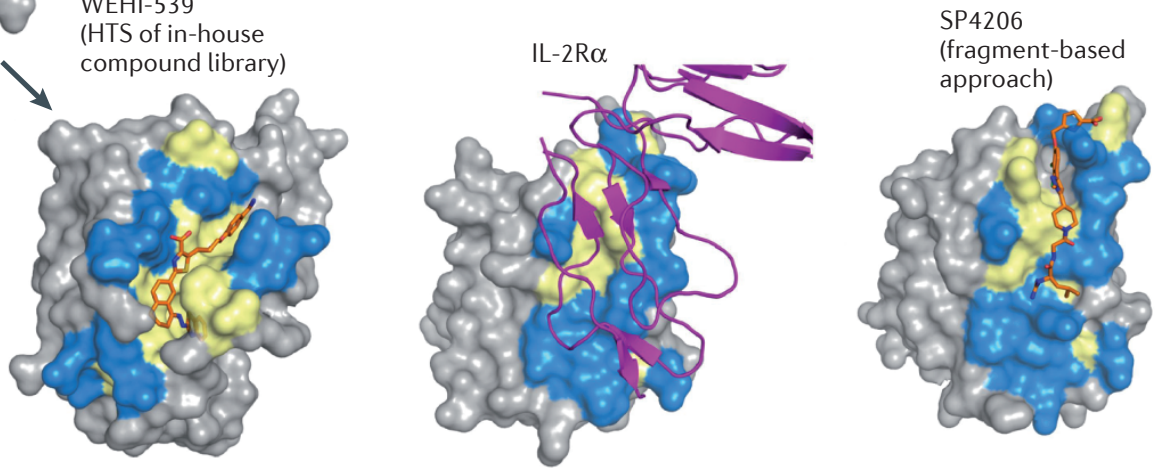

Figure 2 | Cancer-related protein-protein interaction targets $B C L-X_{L}$ and IL-2. $B C L-X_{L}-B A X B H 3$ domain is an example of a 'helix in groove' interaction, and interleukin-2 (IL-2)-interleukin-2 receptor subunit- $\alpha$ (IL-2R $\alpha$ ) is an example of a flat interaction surface. In the figure, the protein to be inhibited is shown as a grey surface and the residues that interact with the natural protein partner are shown in blue (polar residues) and yellow (hydrophobic residues). The same view and colour scheme has been used to highlight the conformational change in the protein interaction surface when it is bound to the interacting partner protein, peptide or small molecule. $\mathbf{a} \mid$ The $B C L-X_{L}$ crystal structure (middle; Protein Data Bank (PDB) ID: 1R2D ${ }^{135}$ ); the complex of BCL-X with the BAX BH3 peptide (magenta; top left; PDB ID: 3 PL7 (REF. 130); half-maximal inhibitory concentration $\left.\left(\mathrm{IC}_{50}\right)=184 \mathrm{nM}^{136}\right)$; the complex of $B C L-X_{L}$ with $B I M \beta 5$, which is a stapled BIM BH3 peptide (magenta, with the linker ('staple') shown as sticks; top right; PDB ID: 2 YQ6 6 (REF. 137); dissociation constant $\left(K_{D}\right)=45 \mathrm{nM}^{137}$ ); the complex of BCL-X $\mathrm{L}_{\mathrm{L}}$ with ABT-737 (shown as sticks, coloured by atom type; bottom left; PDB ID: $\underline{2 Y X J}^{138}$; $K_{D}=0.4 \mathrm{nM}^{91} ; I_{50}=5 \mathrm{nM}^{91}$ ); and the complex of $B C L-X_{L}$ with WEHI- 539 (shown as sticks, coloured by atom type; bottom right; PDB ID: $3 \mathrm{BZR}^{91} ; K_{\mathrm{D}}=0.6 \mathrm{nM}^{91} ; \mathrm{IC}_{50}=1.1 \mathrm{nM}^{91}$ ). $\mathbf{b}$ | The IL-2 crystal structure (top; PDB ID: $1 \mathrm{M} 47$ (REF. 94)); the complex of IL-2 with IL-2Ra (magenta; bottom left; PDB ID: 1 Z92 (REF. 139); inhibition constant $\left(K_{\mathrm{i}}\right)=10.5 \mathrm{nM}^{140}$ ); and the complex of IL-2 with the inhibitor SP4206 (shown as sticks, coloured by atom type; bottom right; PDB ID: 1PY2 (REF. 141); $\left.K_{\mathrm{i}}=68.8 \mathrm{nM}^{140}\right)$. HTS, high-throughput chemical screening.

sensitive radiometric assays such as scintillation proximity assays and FlashPlate (PerkinElmer) ${ }^{17}$, the problem often lies not in the availability of an assay method but in the recreation of the PPI in an in vitro setting. Components can be difficult to isolate in a fully functional form on the scale that is required for HTS, owing to various biological complexities, such as essential cofactors, membrane requirements, multiprotein complexes and so on. Often, one or more protein partners are present as a fragment (for example, as a peptide or a specific domain) in assays, and inhibition of the PPI in vitro might not be recapitulated with the full-length proteins. A greater understanding of the quality of the compound libraries that are used during HTS is also developing as groups merge experimental results from different screening campaigns and investigate common trends. This has led to a better understanding of the chemistries of compounds that frequently lead to false positives and ultimately lead to resources being wasted; in particular, this is exemplified by Baell and Holloway's 'pan assay interference compounds' (PAINS; see below) ${ }^{19}$. Moreover, researchers at F. Hoffmann-La Roche identified zinc-contaminated compounds as giving a false-positive signal in their screen directed against $\mathrm{RAS}^{20}$. On a more positive note for the development of RAS pathway inhibitors, one group has identified a series of benzimidazole compounds through an AlphaScreen assay that selectively bind to the prenyl-binding pocket of phosphodiesterase 6D (PDE $\delta$; also known as GMPPDE $\delta$ ) with nanomolar affinity, and these disrupt the KRAS-PDE $\delta \mathrm{PPI}^{21}$.

Helix-groove binders. The greatest success for HTS so far has been with PPIs in which a helix of one protein binds into a groove of the interacting partner; for example, the $\mathrm{BAX} \mathrm{BH} 3$ domain interacting with BCL- $\mathrm{X}_{\mathrm{L}}$ (REF. 22) 


\section{Box 1 | Hot spots and O-rings}

Globular protein interfaces typically have $1,200-2,000 \AA^{2}$ of buried surface, which is similar in composition to the available surface of typical monomeric proteins. The distribution of polar and lipophilic groups is comparable to a normal protein surface ${ }^{7}$. Packing of residues in the protein interface is usually tight, with a similar density to that of atoms in the hydrophobic core of a protein ${ }^{129}$. This is increased by interfacial water molecules that form polar interactions between the proteins. There is, however, a high degree of variation in the 'flatness' of the interface, with many interfaces having quite well-defined binding sites, such as the helix-binding groove on BCL-X (FIG. 2a). Others have no immediately obvious site of interaction (such as the interleukin-2 interface (FIG. 2b)). However, painstaking experimental studies using mutagenesis and affinity measurement have shown that many of these apparently featureless interfaces contain 'hot spots', which are small clusters of residues that contribute a significant proportion of the overall binding energy in the interaction ${ }^{130}$. The residues in hot spots also show a higher degree of flexibility and motion than the rest of the interfacial residues, which increases their potential for use as drug target $\operatorname{sites}^{131}$. This adaptivity provides a mechanism for optimizing the fit of the protein-protein interaction while at the same time giving a greater opportunity for small-molecule inhibitors to bind to the target protein, thereby potentially inducing the formation of a new pocket with more typical druggable features. Hot spots are usually ringed by a layer of residues (the 'O-ring' (REF. 132)) that almost completely exclude solvent, which means that the hot-spot interactions are driven solely by the residues themselves, without any bridging solvent molecules. Around the O-ring are the 'rim' residues, which form the periphery of the interface and are only partially buried from solvent. FIGURE 4 shows these key features on the structure of the human growth hormone binding protein (GHBP; also known as the extracellular GHR domain)-growth hormone $(\mathrm{GH})$ complex ${ }^{133}$. Hot-spot residues were defined through mutagenesis and binding studies as providing approximately $85 \%$ of the total binding energy of the interaction ${ }^{134}$.

\section{Structure-based drug} design

(SBDD). An approach that uses the three-dimensional

structure of a protein or a protein complex to guide the development of ligands.

Differential scanning fluorimetry

(DSF). An assay that is used to measure the thermal stability of proteins through the binding of a hydrophobic, fluorescent dye to partially unfolded proteins. Changes in the temperature of unfolding in the presence of compounds reflect the stability of a protein-ligand complex.

Structure-activity relationships

(SARs). Relationships between the chemical or three-dimensional structure of molecules and their biological activity.
(FIG. 2a) and p53 interacting with MDM2 (REF. 23). The $\alpha$-helix-binding grooves are surface pockets that are more akin to a classic enzyme-substrate site because of their well-defined and pronounced clefts compared to other types of globular protein interfaces (BOX 1).

The BCL-2 family of proteins are necessary for the regulation of apoptosis or programmed cell death. The family is composed of two related groups - the pro-survival proteins, such as BCL-2, BCL- $\mathrm{X}_{\mathrm{L}}, \mathrm{BCL}-\mathrm{W}$, BCL-B, MCL1 and A1 (also known as BCL-2A1), and the pro-apoptotic proteins, such as BAX, BAK, BOK, BAD, BIM, PUMA and NOXA ${ }^{22}$. Inhibitors of this family of apoptosis regulators were identified by $\mathrm{NMR}^{24}$, MS and $\mathrm{FP}^{25}$, and computational screening ${ }^{26}$. The Nutlins — imidazoline-based compounds that inhibit the interaction between the p53 tumour suppressor and MDM2, which is one of the key repressors of p53 activity - were discovered and developed through screening the interaction of the mouse MDM2 homologue with p53 by $\mathrm{SPR}^{27}$. The proof-of-concept for this PPI target came from screening 12-mer and 15-mer phage display libraries $^{28}$. The minimal length of the p53-derived peptide that was required to retain micromolar inhibition of MDM2 was determined. In addition, modification of the minimal length peptide to include a 6-chloro substituent on the tryptophan residue increased inhibition. These drugs were successfully optimized into mid-nanomolar inhibitors (half-maximal inhibitory concentration $\left(\mathrm{IC}_{50}\right)$ values in the 100-300 $\mathrm{nM}$ range) using structure-based drug design (SBDD $)^{28}$. Further investigation around this series led to the F. Hoffmann-La Roche candidates RG7112 (REFS 23,29) and RG7338 (REF. 30). These and two other MDM2-p53 inhibitors are in clinical trials:
RG7112 (REF. 29) (two active Phase I trials and five completed trials under the name RO5045337; targeting various leukaemias and liposarcoma), RG7338 (REF. 30) (currently in three Phase I studies under the name RO5503781; targeting solid tumours), SAR299155 (REFS 28,31) (currently undergoing Phase I clinical trials; targeting acute myelogenous leukaemia and solid tumours) and MK-8242 (REF. 28) (also known as SCH900242; currently in two Phase I studies; targeting acute myelogenous leukaemia and solid tumours) - see ClinicalTrials.gov. A different HTS approach was taken by Johnson \& Johnson, in which they used differential scanning fluorimetry (DSF) to screen 338,000 compounds; from these, 116 benzodiazepinedione compounds were selected for further analysis using a fluorescent peptide displacement assay that was designed to detect specific inhibitors of the MDM2-p53 interaction ${ }^{32}$. They used an MDM2 peptide consisting of residues 17 to 125 , which included the minimal p53 binding domain ${ }^{33}$. A hit-to-lead optimization programme established extensive structure-activity relationships (SARs) and the importance of the absolute stereochemistry for their lead series, but these compounds showed weak cellular activity and were not developed further.

Another interesting example of this class of PPI being addressed by HTS is provided by the 14-3-3 proteins ${ }^{34}$. These eukaryotic adaptor proteins, which are involved in the regulation of cell cycle control, signal transduction, protein trafficking and apoptosis, act as functional dimers, with each monomer containing an amphipathic groove that accommodates interaction motifs on their partner proteins. In one study, a surface-based fluorescence assay of 14-3-3 interacting with a plant (Nicotiana plumbaginifolia) plasma membrane $\mathrm{H}^{+}$-ATPase-2 (PMA2) was used to screen a 37,000 -compound library ${ }^{35}$ for compounds that stabilized the 14-3-3 dimer. By contrast, competitive inhibitors that block the amphipathic groove and prevent formation of the active 14-3-3 dimer have been identified through the screening of a hybrid peptide and smallmolecule library ${ }^{36}$. This demonstration that the same PPI can be successfully addressed by modulators that block or increase the protein interaction makes it clear that assay development for PPI HTS programmes requires extremely careful planning.

Non-helical-groove binders. There are now excellent examples of small-molecule inhibitors that have been developed to compete with non-helical-groove binders. For example, the X-linked inhibitor of apoptosis (XIAP) has a downstream role in the apoptosis pathway and regulates the expression of the 'executor' cysteine-aspartic acid proteases (caspases) ${ }^{37}$. Antagonists of XIAP were identified by an enzymatic derepression assay of caspase 3 func$\operatorname{tion}^{38}$. They were confirmed to be specific for inhibiting the binding to caspase 3 by ELISA assays of the interaction of XIAP with endogenous XIAP inhibitors, such as second mitochondria-derived activator of caspases (SMAC). SMAC is known to interact with a deep groove in XIAP in an extended conformation ${ }^{39}$. Other XIAP antagonists were identified by NMR studies of XIAP-peptide complexes, with binding affinities of compounds measured by $\mathrm{FP}^{40}$. 
Medicinal chemistry optimization The process in which chemists synthetically modify lead compounds to improve therapeutic properties such as efficacy and specificity for the target protein, as well as pharmacological properties such as bioavailability and absorption, distribution, metabolism and excretion (ADME) or toxicity.

In silico combinatorial chemistry

The virtual synthesis of a large number of chemical or

biological entities using a small set of reagents together in all combinations. The resultant libraries are used for virtual or in silico screening.

Calculated LogP

(cLogP). The calculated base-10 logarithm of the relative partition of a compound in an organic phase (octanol) versus an aqueous phase (water), which is usually reported at $25^{\circ} \mathrm{C}$. cLogP values are generally reliable, and the parameter is used as an indicator of the solubility of the compound

Polar interactions The interactions between two chemical groups that both contain an electric dipole or multipole moment.

Hydrophobic interactions Interactions of nonpolar (unionized and uncharged) regions of molecules with each other. The interactions have contributions from both dispersion forces and van der Waal's effects; they are entropy-driven through solvent exclusion.
An interesting recent example of the combined use of HTS and structural biology to find potent PPI inhibitors is that of the disruption of the complexes that are formed by mixed lineage leukaemia (MLL) fusion proteins and the tumour suppressor protein menin, which are complexes found in the development of human acute leukaemias ${ }^{41}$. A peptide fragment of MLL was shown to interact with menin in a deep groove, where it adopts a U-shaped conformation with a single $\beta$-turn. A collection of 49,000 small molecules was screened using an FP assay to target the complex ${ }^{42}$. The most potent compound $\left(\mathrm{IC}_{50}=1.9 \mu \mathrm{M}\right)$ that was identified belonged to the thienopyrimidine chemical class. Initial medicinal chemistry optimization led to a more potent compound, MI-2, which inhibited the interaction with an $\mathrm{IC}_{50}$ of $446 \mathrm{nM}$. The crystal structure of menin that was complexed with MI-2 showed that the inhibitor mimicked many of the key interactions that MLL has with menin, and it provided the basis for the development of a potent nanomolar inhibitor (dissociation constant $\left(K_{\mathrm{d}}\right)=22 \mathrm{nM}$ ) that showed strong inhibition of cell proliferation and differentiation in leukaemia cells in which $M L L$ is translocated.

\section{Computational approaches to modulating PPIs}

Virtual screening (VS; also known as in silico screening) is the process of searching a computer-based collection of chemical entities that have the greatest potential to interact with the protein target ${ }^{43}$ and, in the context of this Review, to modify a specific PPI. VS can be used as a stand-alone method to identify potential hits or as a prelude to HTS, which is still a relatively expensive process (FIG. 1). Using VS before HTS is beneficial because it allows a more focused and enriched compound set to be evaluated in the bioassay. The in silico compound library can be derived from several sources, such as proprietary in-house compound collections, commercial and noncommercial supplier databases (see Supplementary information S4 (table) and Further information for examples) and even sets of 'virtual' compounds that arise from in silico combinatorial chemistry. It is now common for in silico compound libraries to comprise millions of compounds. Compounds that contain undesirable physicochemical properties are typically removed from the in silico compound library by applying filters; for example, excluding all metal-containing compounds, known promiscuous compounds (PAINS) ${ }^{19}$ and those with a molecular mass above $1,000 \mathrm{Da}$ or a calculated $\operatorname{LogP}(\operatorname{cog} P)>6$. The nature of the search query for VS depends on whether the structure of the target protein is known (FIG. 1). When the structure of the target protein is available (from X-ray crystallography, NMR or homology modelling) the interaction surface can be searched (screened) using a computational algorithm that assesses the ability of each compound in the in silico library to interact with the experimentally determined protein surface 'hot spots' (BOX 1 describes hot spots and the painstaking experimental methods that are used to identify them). This process is also known as 'protein-compound docking.' Given the plastic nature of protein-protein interfaces and the availability of cheap computational power, the current trend is to screen ensembles of potential protein conformations rather than a single protein model. These ensembles can be derived from multiple crystal structures, from snapshots of molecular dynamics simulations or from NMR ensembles ${ }^{4-47}$. The fit of the compound to the protein interaction surface is evaluated or 'scored' on the basis of criteria that include shape complementarity, polar interactions, hydrophobic interactions and van der Waal's interactions. The compound score is used to rank the quality of the interaction of each compound with the target site. An excellent review of the methodology of protein-compound docking, docking software and scoring algorithms has recently been published ${ }^{43}$. The ranked compounds from the VS process must then be assayed for their ability to modulate the target PPI before undergoing a traditional medicinal chemistry optimization process. The number of compounds that are selected for biological screening depends on the resources (for example, funds and facilities) of the investigators (for example, those in academic research or working in industry) and the throughput of the bioassay.

Numerous early drug discovery examples of VS for modulators that targeted cancer-related PPIs have been published, including for XIAP-caspase 9 (REF. 48), the BCL-2-BAK BH3 domain ${ }^{49}$ and the urokinase plasminogen activator receptor (uPAR)-urokinase-type plasminogen activator (uPA) interaction ${ }^{45}$.

$\mathrm{XIAP}$ is upregulated in many cancers, including acute myeloid leukaemia, as well as breast, pancreas, prostate and solid tumours ${ }^{11,50}$ (TABLE 1). In the case of XIAP, the compound embelin (see Supplementary information S4 (table)) was identified as a cell-permeable, low molecular mass inhibitor of the XIAP-caspase 9 interaction ${ }^{48}$. The program DOCK $^{51}$ was used to virtually screen a library that comprised 8,000 structurally diverse small molecules against a model of the SMAC protein binding site that was extracted from a crystal structure of the XIAP BIR3 domain-SMAC complex. The authors used their in-house scoring function, 'X-score', to rank the compounds and the top 200 were considered to be potential inhibitors of the XIAP BIR3 domain. From the top 200 ranked compounds, 36 were obtained and their affinities were determined in an FP binding assay. The authors did not disclose how these 36 compounds were chosen over the other 164 . Although the authors stated that five of the 36 compounds screened in the FP binding assay showed affinity for the XIAP BIR3 domain, data were reported for only one compound. Embelin was reported to be the strongest binder, with an $\mathrm{IC}_{50}$ of $4.1 \mu \mathrm{M}$ (see Supplementary information S4 (table)), which was comparable to the binding affinity of the natural 9-mer SMAC peptide $\left(\mathrm{IC}_{50}=2.8 \mu \mathrm{M}\right)^{48}$. Having established that embelin bound to the target XIAP protein, the ability of the compound to inhibit cell growth in prostate cancer cells (PC-3 and LNCaP) and to induce apoptosis through the activation of caspase 9 in PC-3 cells was evaluated ${ }^{48}$. Embelin inhibited PC-3 and $\mathrm{LNCaP}$ cell growth $\left(\mathrm{IC}_{50}=3.7 \mu \mathrm{M}\right.$ and $5.7 \mu \mathrm{M}$, respectively) and induced apoptosis in PC-3 cells via the activation of caspase 9 (a 10 -fold and 20-fold increase in 


\author{
Pharmacophore \\ A description of molecular \\ features for a binding \\ interaction and their relative \\ position in three-dimensional \\ space. Pharmacophores can be \\ derived from either the protein \\ receptor site (protein-based \\ pharmacophore) or from a \\ superimposition of known \\ compounds (compound-based \\ pharmacophore).
}

the level of activated caspase 9 was induced by a 42-hour treatment with $20 \mu \mathrm{M}$ and $40 \mu \mathrm{M}$ embelin, respectively) in a dose-dependent manner. Identifying embelin as an XIAP BIR3 domain PPI inhibitor means that the compound could function as the starting point for a medicinal chemistry optimization programme to improve activity and pharmacokinetic properties.

Inhibitors of the anti-apoptotic protein BCL-2 are currently being used to treat various cancers, including breast cancer, chronic lymphocytic leukaemia, lymphoma, prostate cancer, small-cell lung cancer and solid tumours $^{52}$ (TABLE 1). Small-molecule inhibitors of the BCL-2-BAK BH3 domain interaction were identified from the US National Cancer Institute DIS 3D database of 206,000 compounds $^{49}$. The BH3 $\alpha$-helix binding cavity in a homology model of the BCL-2 protein was screened using DOCK ${ }^{51}$. The energy scoring function in DOCK was used to rank the compounds and the top 500 were considered to be potential BCL-2 inhibitors. Chemical samples of 80 of the top 500 compounds were requested from the US National Cancer Institute; how these 80 compounds were selected was not disclosed, but only 35 were available. These compounds were tested in an FP binding assay and seven were shown to have affinity for BCL-2; the strongest binder had an $\mathrm{IC}_{50}$ of $1.6 \mu \mathrm{M}$ (see Supplementary information S4 (table) $)^{49}$. The seven compounds were then investigated for HL-60 cell viability and proliferation (HL-60 is a human myeloid leukaemia cell line that expresses high levels of BCL-2 protein); for the inhibition of cell viability, six of the compounds had an $\mathrm{IC}_{50}<50 \mu \mathrm{M}$ and one compound inhibited cell growth with an $\mathrm{IC}_{50}$ of $4 \mu \mathrm{M}^{49}$. BCL- 2 is overexpressed in breast, prostate and other forms of cancer, and further optimization of these compounds through SBDD would be required to produce potential clinical candidates.

uPAR is highly expressed in most cancers ${ }^{53}$ and the uPAR-uPA interaction has been implicated in tumour formation and progression ${ }^{45}$. In a search for small molecules that are capable of inhibiting the UPAR-uPA interaction, the binding cavities from two uPAR crystal structures were screened against a library of nearly 5 million commercially available compounds ${ }^{45}$. Seven different scoring functions were used to select the top 10,000 compounds. These 10,000 compounds were further virtually screened using a multiple protein conformer strategy, whereby an ensemble of 50 uPAR conformations that were generated by molecular dynamics simulations were searched using the programs AutoDock4 (REF. 54) and Glide (version 5.5; Schrödinger). The docked complexes were finally scored and ranked using Glide SP; the 250 highest ranked compounds were clustered by similarity and the highest scoring compound from the top 50 clusters was purchased and screened in an FP binding assay. Of the 50 compounds screened, three showed affinity for uPAR, with the strongest binder (IPR-456) having an inhibition constant $\left(K_{\mathrm{i}}\right)$ of $140 \mathrm{nM}$ (see Supplementary information S4 (table) $)^{45}$. The authors went on to show that IPR-456 inhibited both the uPAR-uPA PPI interaction and cell invasion in the breast cancer cell line MDA-MB-231, which overexpresses uPAR $\left(\mathrm{IC}_{50}\right.$ for inhibiting invasion estimated to be $30 \mu \mathrm{M})$. Although IPR-456 is a useful chemical tool compound to probe the role of the uPAR-uPA PPI interaction in blocking metastatic processes such as invasion, further medicinal chemistry optimization will be required to develop clinical candidates.

Pharmacophore searching. An alternative VS approach is to identify key features from one of the proteins involved in the interaction and represent this motif as a pharmacophore (FIG. 1). The protein-based pharmacophore can then be used to search the in silico compound library and identify compounds that satisfy the pharmacophoric elements. Each compound is scored against how well it matches these elements and ranked. The highest ranked compounds can then be assessed in an appropriate bioassay ${ }^{4755-59}$. An example of the protein-based pharmacophore approach is the identification of substituted 1,2,4-triazoles as inhibitors of the S100A10-annexin A2 protein interaction (see Supplementary information S4 (table)) $)^{55}$. This PPI was shown to be essential for the recruitment of macrophages to tumour sites and is implicated in the process of neo-angiogenesis ${ }^{60}$. S100A10 mediates the recruitment of macrophages to inflammatory stimuli, while annexin A2 is an autocrine factor that is involved in osteoclast formation and bone resorption ${ }^{61}$. S100A10 has recently been identified as a potential therapeutic target in colorectal cancer ${ }^{62}$. A pharmacophore model that represented the amino acid interactions made by the amino-terminal residues of annexin A2 to the S100A10 protein interface was generated from the crystal structure of the S100A10annexin A2 complex. A library of 704,000 commercially available compounds was screened against the pharmacophore (see Supplementary information S4 (table)) and 586 compounds that fitted the pharmacophore were identified. These compounds were then docked into the defined annexin A2-binding site on the S100A10 protein surface using the program GOLD ${ }^{63}$. One hundred and ninety compounds were selected on the basis of both the ranked pharmacophore fit and GOLD docking scores for screening in a competitive FRET assay. Three compounds were confirmed as inhibitors of the S100A10annexin A2 interaction ( $\mathrm{IC}_{50}$ values of $24 \mu \mathrm{M}, 66 \mu \mathrm{M}$ and $90 \mu \mathrm{M})$ and provided the basis for a medicinal chemistry optimization programme.

Even in the absence of structural information about a PPI, it is still possible to perform VS by using the chemical structures of known active compounds that have been identified using other approaches, such as HTS (FIG. 1). Key chemical features in the active compounds can be used to generate a compound-based pharmacophore (FIG. 1), which in turn can be used to search in silico compound libraries ${ }^{64-66}$ in a similar manner to that described above for protein-based pharmacophores. An example of the compoundbased pharmacophore searching approach is the identification of tubulin polymerization inhibitors (see Supplementary information S4 (table) $)^{65}$. Compounds that inhibit tubulin polymerization are allosteric PPI inhibitors, in that they do not bind at the 
$\alpha$-tubulin- $\beta$-tubulin heterodimer interface but they bind to different regions on the $\alpha$-tubulin- $\beta$-tubulin heterodimer, and this binding in turn regulates tubulin oligomerization. Tubulin inhibitors have been used for many years ${ }^{11}$ to treat cancers such as bladder cancer, breast cancer and prostate cancer, and some recent examples are given in TABLE 1. In the above computational approach example, a compound-based pharmacophore was generated from a training set of 21 compounds with $\mathrm{IC}_{50}$ values ranging from $1.2 \mathrm{nM}$ to $6,000 \mathrm{nM}$ for the inhibition of human oral squamous carcinoma KB cells using CATALYST software (version 4.10; Accelrys). The pharmacophore was used to screen a compound database of 130,000 compounds, and 1,000 compounds with the best fit to the pharmacophore features were examined further. Compounds were visually examined for any structural features that might sterically clash with the tubulin binding site, and these compounds were eliminated from the compound list. The remaining 142 compounds were screened against the $\mathrm{KB}$ cell line for their anti-proliferative activities; four compounds inhibited the $\mathrm{KB}$ cell line with $\mathrm{IC}_{50}<6 \mu \mathrm{M}^{65}$. The most active compound (see Supplementary information S4 (table)) was also shown to be a tubulin inhibitor in an in vitro tubulin polymerization assay
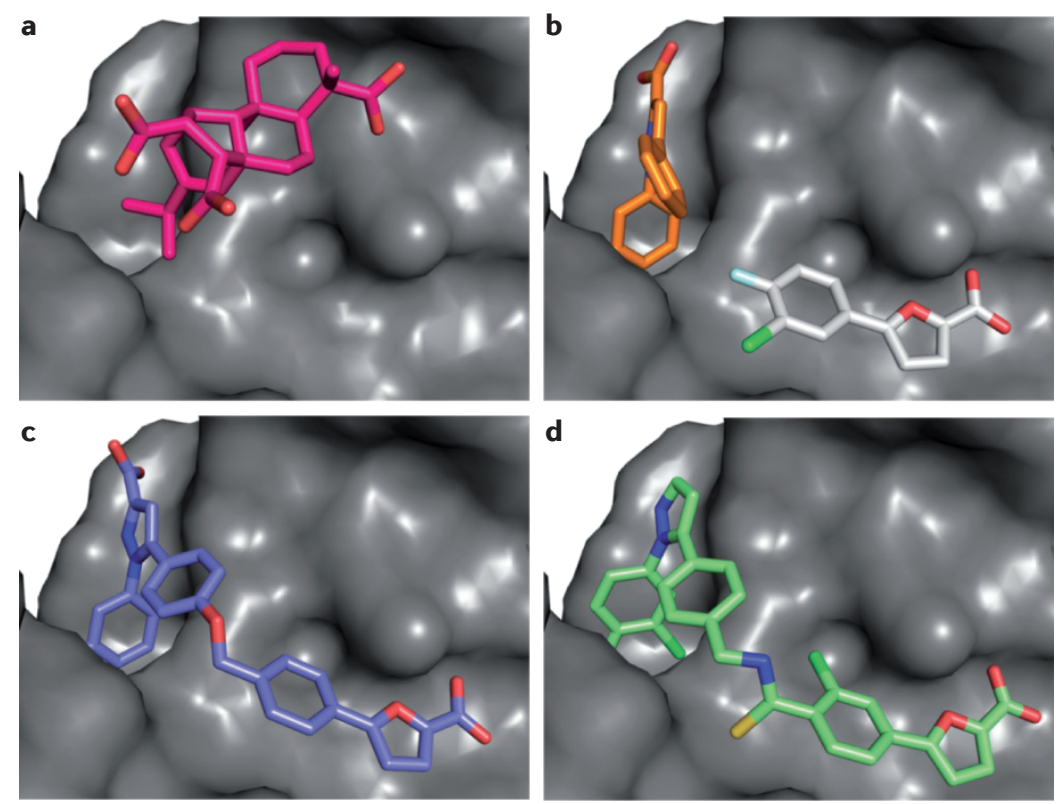

Figure 3 | Optimizing protein-ligand interactions using fragment-based screening. An illustration of a fragment linking approach to develop inhibitors of the replication protein A (RPA; grey molecular surface) protein-protein interaction with partner proteins that are involved in the DNA-damage response, such as p53, RAD9, ATR-interacting protein (ATRIP) and MRE11 (REF. 79). a |A docked model of a high-throughput chemical screening (HTS) 'hit', fumaropimaric acid (pink), bound to RPA (fluorescence polarization (FP)-determined dissociation constant $\left.\left(K_{\mathrm{D}}\right)=18.3 \mu \mathrm{M}^{142}\right)$. $\mathbf{b} \mid$ Crystal structures of fragment hits bound to RPA (Protein Data Bank (PDB) ID: LUUV $^{79}$; NMR-determined $K_{\mathrm{D}}=580 \mu \mathrm{M}$ (orange) and $K_{D}=1,400 \mu \mathrm{M}$ (white) $)^{79}$. Each fragment has fewer but more efficient and optimized interactions with the protein target compared to the HTS hit. $\mathrm{c}$ |By linking these fragments, the binding affinity was improved (the crystal structure shown is of PDB ID: 4 LUZ; purple; NMR-determined $K_{D}=26 \mu \mathrm{M}$; FP-determined $\left.K_{D}=20 \mu \mathrm{M}^{79}\right)$. d | Further optimization gave the crystal structure of a compound (green) with an FP-determined $K_{D}$ of $0.19 \mu \mathrm{M}$ (PDB ID: $\underline{4 \mathrm{LWC}^{79}}$ ). with an $\mathrm{IC}_{50}$ of $4.4 \mu \mathrm{M}$. The four compounds with antiproliferative activity would provide an ideal starting point for a medicinal chemistry optimization programme.

The VS approaches described here are typically used in the early drug discovery phase to identify compounds with some activity for the protein target. The same computational methods have been applied for many years to the traditional cancer-related protein targets, such as $\mathrm{G}$ protein-coupled receptors, protein kinases and enzymes ${ }^{43}$. VS should essentially be considered as an early lead generator, and compounds with activity for the protein target should necessarily undergo substantial medicinal chemistry optimization, such as scaffold hopping and analogue exploration.

\section{Fragment-based design for modulating PPIs}

Fragment-based screening uses a different but complementary approach to HTS. Fragments are low molecular mass compounds $(<300 \mathrm{Da})$ that typically comprise one or two fused or linked ring systems with one or two functional groups ${ }^{67-76}$. The rationale behind fragment screening is that the molecules in fragment libraries explore chemical space more efficiently and are more likely to form an optimal set of interactions with a target protein than the larger and more complex HTS compounds (FIG. 3). The downside of the simpler interactions is that the initial hits typically have a very low affinity $\left(K_{\mathrm{D}}=100 \mu \mathrm{M}\right.$ to $10 \mathrm{mM}$ ) and therefore require specialized and sensitive techniques to measure binding interactions ${ }^{77}$. Fragments also tend to be more promiscuous than compounds that are identified through HTS, as the simpler chemistry is likely to form a match with multiple protein binding sites. Ideally, a structure-guided approach is used to develop a fragment hit to counter the issue of promiscuity. An emerging example of this is the development of inhibitors of replication protein A (RPA), which is involved in the DNA-damage response $\mathrm{f}^{78,79}$. Researchers at Vanderbilt University, Nashville, Tennessee, USA, determined the crystal structures for several fragment hits, which they then linked and optimized to develop a lead compound with a sub-micromolar $K_{\mathrm{D}}$ (REF. 79) (FIG. 3). Optimization of detection techniques and increased knowledge of methods for fragment growth and elaboration have meant that fragment-based screening is now a routine technique in the pharmaceutical industry and is increasingly being used in academia.

The small size, low affinity and binding promiscuity of fragments means that sensitive methods are needed to detect and measure interactions. Methods including protein-based or ligand-based $\mathrm{NMR}^{80}$, X-ray diffraction $^{81,82}$ and SPR ${ }^{83-85}$ are well-established for the detection of fragment binding ${ }^{75}$. DSF, AlphaScreen, FRET, FP and microscale thermophoresis are among techniques that are being explored for measuring fragment binding ${ }^{14,86,87}$. Traditional biochemical assays have also been adapted for fragment screening in an approach that has been dubbed 'high concentration screening. In this approach, fragments are tested in established biochemical assays for a given protein target but at a much higher concentration than normal assays (typically $250 \mu \mathrm{M}$ to $5 \mathrm{mM}$ ) ${ }^{87,88}$. Although activity in a bioassay is the gold standard for 
identifying a PPI modulator, using this approach for fragments can lead to a high rate of false positives owing to compound aggregation that interferes with the assay, and can be confounded by the lack of adequate solubility for fragment compounds in suitable assay buffers. The development of the BCL-2 and BCL- $\mathrm{X}_{\mathrm{L}}$ inhibitor ABT-263 (Navitoclax) ${ }^{89}$, which is currently in Phase II clinical trials for the treatment of various lymphomas and leukaemias, is among the first success stories to originate from fragment screening (TABLE 1). Researchers at Abbott laboratories ${ }^{24}$ used a technique called 'SAR by NMR' (REF. 71) to identify two fragments that bound adjacent to one another in the $\mathrm{BH} 3 \alpha$-helix-binding groove of $B C L-X_{L}$. These compounds were developed into the preclinical candidate ABT-737 (FIG. 2a) before being further optimized for oral bioavailability to ABT-263 (REF. 89). Efforts are now focused on introducing selectivity for individual members of the BCL-2 protein family by using a combination of directed fragment libraries ${ }^{90}$ and peptide-mimetic scaffold libraries ${ }^{91}$. Researchers are also using NMR techniques to probe conformational changes of the $\mathrm{BCL}-\mathrm{X}_{\mathrm{L}}$ protein during fragment and inhibitor binding to increase specificity for particular BCL-2 protein family members ${ }^{92}$.

An alternative fragment-based approach for PPI modulator development is molecular tethering ${ }^{93}$. Tethering uses a specific anchor point, such as a cysteine, that is adjacent to the binding site of interest, as well as a reactive group (a sulphydryl group in the case of a cysteine anchor point) on the fragment to form a covalent link. Binding can be confirmed using MS and visualized using X-ray crystallography. Tethering was used to identify inhibitors of the cytokine signalling molecule IL-2 (REFS 94,95). Arkin and colleagues ${ }^{94,95}$ used tethering to screen for novel compounds with tractable chemistry and that bound to IL-2 in a manner distinct from a known inhibitor. From a modest lead compound (active between $500-600 \mu \mathrm{M}$ in an ELISA assay) an inhibitor with an $\mathrm{IC}_{50}$ of $60 \mathrm{nM}$ was developed - guided by SBDD. The ligand-free structure of IL-2 is flat and featureless (FIG. 2b), and it was only once a crystal structure of IL-2 in complex with a known inhibitor was obtained that the PPI hot spot became apparent ${ }^{93-95}$.

Compound libraries that are prepared from extracts of natural products such as plants, animals or parts thereof. Compounds in a natural product library may be present as crude extracts, fractionations or purified products.

Stapled BIM $\beta 5$ peptides Stapled BIM $\beta 5$ peptides have been chemically locked into a stable conformation by the introduction of an intramolecular linker between the residues. This modification results in a peptide that is resistant to proteases, has increased cell penetration, improved pharmacokinetics and, usually, a high affinity to the target protein surface. to evolve to exploit the insights that are gained from the success or failure of compound classes and from the physicochemical profile of the hit series of compounds that emerge.

\section{Biological approaches to modulating PPIs}

Biologicals are medicinal products that include protein-based drugs, peptides, aptamers and other macromolecules. The main advantages of biologicals as therapeutics are their high target specificity and potency. They also often share a metabolic pathway with endogenous macromolecules, which, along with their high specificity, results in a low level of systemic toxicity. Biologicals are particularly useful for PPI modulation, as they can be readily tuned to bind to a large variety of protein surfaces, and they are often used as a starting point for PPI drug discovery programmes.

Protein-based drugs. Examples of protein-based drugs include antibodies and other entities such as enzymes, growth factors, hormones, interferons, interleukins and engineered protein scaffolds ${ }^{100,101}$. Antibodies have become the fastest growing class of biological therapeutics, particularly in oncology (see Supplementary information S1 (table)). Antibodies that bind with high affinity and specificity to their targets elicit an antitumour effect via immune stimulation, the focused delivery of conjugated toxins or by modulating PPIs on the surface of target tissues. The limitations of proteinbased drugs include a tendency to elicit a systemic immune response before reaching the drug target (particularly with extended dosing) and an inability to access intracellular targets ${ }^{102,103}$. Difficulties in modifying pharmacokinetic characteristics after production, formulation issues and excessive production or purification steps complicate the manufacture of protein-based drugs and add substantial expense ${ }^{104-107}$.

Peptide-based modulators. Compared with proteinbased drugs, peptides are less likely to prompt any serious immune response and are generally cheaper and quicker to produce. Indeed, more than 100 peptidebased drugs are currently on the market, with annual sales in excess of $\$ 40$ billion per year, which represents $10 \%$ of the annual sales for all available drugs ${ }^{108}$ (see Supplementary information S2 (table)). In spite of this success, limitations to accessing intracellular targets and unfavourable pharmacokinetic profiles mean that peptides are often used as a starting point to develop mimetics and non-peptide drugs ${ }^{109}$. Peptide modulators of PPIs have been identified through various approaches, including rational design, as well as screening random and biased peptide libraries ${ }^{110}$.

The rational design of peptides as PPI modulators stemmed from the observation that many PPIs involve a continuous epitope of one partner and a well-defined groove or series of specific small pockets on the target protein surface (BOX 1; FIG. 4). Perhaps the most wellknown example of this is the development of the stapled BIM $\beta 5$ peptides (FIG. 2a) as rationally designed inhibitors of BCL- $\mathrm{X}_{\mathrm{L}}$ (REF. 111). These peptides have since been 
used to develop peptide mimetics and have aided in the development of small-molecule BCL-2-selective inhibitors $^{91,112}$. The pro-apoptotic BH3-only protein NOXA provides a more recent example of a case in which rational design has been successfully used to increase the potency, selectivity, proteolytic stability and cell permeability of a peptide ${ }^{113}$. The $\alpha$-helix of NOXA binds to the BCL-2 family member MCL1 with high affinity and selectivity. MCL1 has been implicated in multiple cancers and has specific clinical implications for chronic myelogenous leukaemia and multiple myeloma. Guided by X-ray crystallography, a cysteine-mediated crosslink was used to stabilize the NOXA $\alpha$-helical peptide. However, the stabilized peptide was still not cellpermeable, and further structure-based refinement of the peptide was carried out. By replacing solventexposed residues and methylating the peptide backbone,
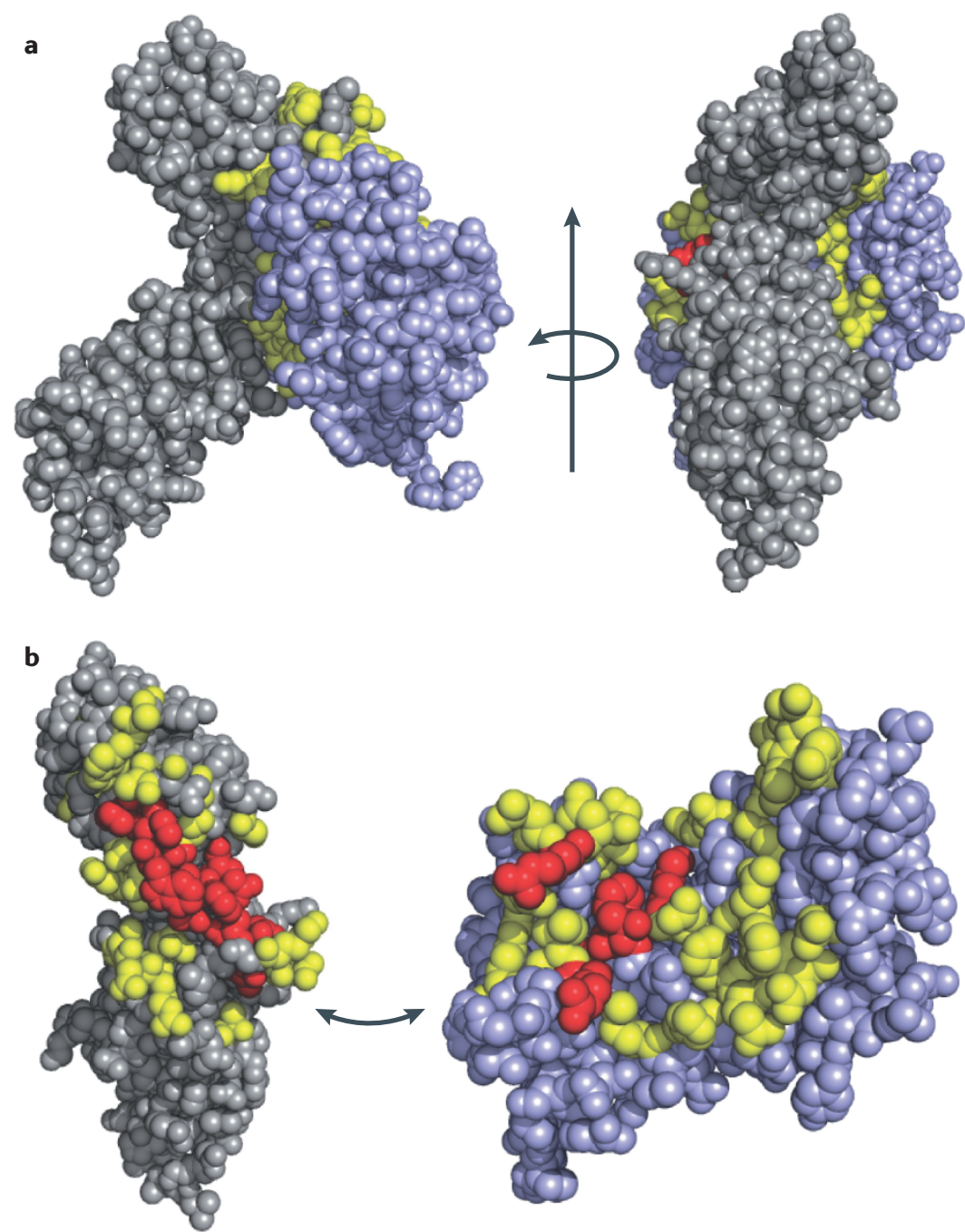

Figure 4 | Hot spots and O-rings at the protein-protein interface. a |Orthogonal views of the human growth hormone binding protein (GHBP)-growth hormone $(\mathrm{GH})$ complex (Protein Data Bank (PDB) ID: $3 \mathrm{HHR}^{133}$ ), with the proteins depicted as atom spheres coloured either purple (GH) or grey (GHBP) except for the 'hot spot' (red) and 'rim' (yellow) residues. Hot spots are usually ringed by a layer of solvent-excluding residues called the 'O-ring', and around the O-ring are the rim residues. $\mathbf{b}$ | The complex is shown opening to expose the interacting surface. a peptide mimetic with a 65 -fold increase in inhibitory activity and a $>200$-fold selectivity for MCL1 over other BCL-2 protein family members was obtained. Examples such as this illustrate the subtlety that is involved in the rational design of peptides into potential therapeutics that target intracellular PPIs.

Peptide modulators have also been discovered through screening techniques, including alanine scanning mutagenesis and phage screening ${ }^{109,110}$. Phage screening identifies linear peptide epitopes that are expressed on the surface of filamentous bacteriophage viruses. Using a random bacteriophage library with the target of choice, phages that have weak peptideprotein target interactions are selected and used to infect colonies of bacteria. During the infection, random substitution occurs in the surface epitopes, and then additional cycles of more stringent selection-replication of the phage progeny are carried out. The end result is a set of phage-carrying peptide sequences that have been tuned by evolution to bind strongly to the target protein ${ }^{114}$. The identified sequence (or sequences) can be directly used as a peptide ligand or further developed by subsequent modification and adaptation. For example, as mentioned above, phage screening was used to create the pharmacophore model behind the current Phase I MDM2-p53 inhibitors ${ }^{28}$. These inhibitors are being sought as tumour-selective drugs for multiple cancer types ${ }^{115}$. A screen of phage display peptide libraries identified a sequence with a 28 -fold greater inhibition of the MDM2-p53 interaction than the wild-type $\mathrm{p} 53$-derived peptide. A crystal structure of the N-terminal domain of MDM2 bound to a wild-type p53-derived peptide showed important structural motifs, such as a type $1 \beta$-turn, that were contained within the peptide. The phage-derived peptide was modified through cysteine-mediated crosslinking chemistry and $N$-methylation of solvent-exposed residues to adopt these motifs, which resulted in a peptide with a 63 -fold greater potency $\left(\mathrm{IC}_{50}\right.$ of $\left.5 \mathrm{nM}\right)$ than the wild-type-derived peptide ${ }^{116}$. These peptides did not reach the clinic owing to poor membrane permeability and physiological stability, but they contributed to the design of non-peptidic inhibitors that are in early phase clinical trials.

Aptamers as PPI modulators. Aptamers are synthetic oligonucleotides that are usually identified through multiple rounds of selection and amplification in a similar way to phage display libraries. Aptamers can be developed to bind to their protein targets with extremely high affinity and have the capacity to modulate PPIs in a similar manner to peptides and antibodies $^{117}$. Like antibodies, aptamers are sought not only as therapeutics but also as drug conjugates for targeted drug delivery and biomarker identification ${ }^{118}$. The key advantages that aptamers have over antibodies are that they are relatively small, comparatively inexpensive, free from cell-culture-derived contaminants and essentially non-immunogenic. Aptamers can also be developed against almost any protein target, including toxins, molecules that do not elicit an immune response 
Allosteric binding sites

Sites on a protein surface that influence the biological

function of a protein upon binding of a regulatory

substance but that are not considered to be the proteinprotein interaction site or the enzymatic or receptor active site. and small epitopes for which antibodies cannot be raised. Several aptamers for use in cancer patients have been successfully taken to the market or are currently undergoing clinical trials (see Supplementary information S3 (table)). For example, ERBB2-specific anticancer aptamers have been recently developed ${ }^{119-123}$ to deliver small interfering RNAs that target BCL-2 to breast cancers ${ }^{124}$, and aptamers that target plateletderived growth factor (PDGF) have been developed to be used in conjunction with traditional kinase inhibitors, such as imatinib mesylate ${ }^{125}$, potentially for the treatment of patients with gastrointestinal tumours ${ }^{126}$. These studies highlight the versatile selection process, low production cost and low batch-to-batch variability that make aptamers an attractive enterprise for clinical application.

\section{Conclusions and future directions}

Approaches to identify and target PPIs for therapeutic development have gathered pace over the past few years. This development is likely to continue in light of pharmaceutical industry analyst predictions that worldwide sales of small-molecule PPI modulators are set to exceed
$\$ 800$ million per annum by 2018 (REF. 5). There is cause for much optimism, particularly for cancer in which progress has been perhaps the most dramatic. Although only a few small-molecule drugs that modulate PPIs have reached human clinical trials to date, there has been exciting progress in developing the appropriate methodology - for example, in fragment screening, compound library design and in peptide mimetics that should in future lead to the development of better cancer-targeted drugs. Furthermore, evidence is emerging that PPIs can be indirectly disrupted through the binding of small molecules at allosteric binding sites ${ }^{127}$, some of which engage 'cryptic' pockets, which are not present in crystal structures of the uncomplexed protein target ${ }^{128}$. The fragment screening approach is proving a powerful means to discover these conformationally adaptable pockets. As a class, PPI modulators tend to be larger than typical orally available drugs ${ }^{8}$. A challenge for the future will be finding ways to optimize the pharmacokinetic properties, such as absorption, distribution, metabolism and excretion, of PPI modulators early in the discovery process to ensure that the compounds are suitable for the clinic.
1. Baker, N. M. \& Der, C. J. Cancer: drug for an 'undruggable' protein. Nature 497, 577-578 (2013).

2. Raj, M., Bullock, B. N. \& Arora, P. S. Plucking the high hanging fruit: a systematic approach for targeting protein-protein interactions. Bioorg. Med. Chem. 21 4051-4057 (2013).

3. Wells, J. A. \& McClendon, C. L. Reaching for high-hanging fruit in drug discovery at proteinprotein interfaces. Nature 450, 1001-1009 (2007).

The first author of this review was a pioneer in the discovery of hot spots in protein-protein interfaces, and this review demonstrates the utility of this discovery with several early examples of small-molecule disruptors.

4. Garner, A. L. \& Janda, K. D. Protein-protein interactions and cancer: targeting the central dogma. Curr. Top. Med. Chem. 11, 258-280 (2011).

5. Meier, C., Cairns-Smith, S. \& Schulze, U. Can emerging drug classes improve $R \& D$ productivity? Drug Discov. Today 18, 607-609 (2013).

6. Zhang, Q. C. et al. Structure-based prediction of protein-protein interactions on a genome-wide scale. Nature 490, 556-560 (2012)

7. Janin, J., Bahadur, R. P. \& Chakrabarti, P. Proteinprotein interaction and quaternary structure. Q. Rev. Biophys. 41, 133-180 (2008)

8. Jubb, H., Higueruelo, A. P., Winter, A. \& Blundell, T. L. Structural biology and drug discovery for proteinprotein interactions. Trends Pharmacol. Sci. 33. 241-248 (2012)

This is a timely review on the nature of protein-protein interfaces, with a major focus on fragment screening as a method to disrupt PPIs.

9. Valkov, E., Sharpe, T., Marsh, M., Greive, S. \& Hyvonen, M. Targeting protein-protein interactions and fragment-based drug discovery. Top. Curr. Chem. 317, 145-179 (2012).

10. Silvian, L., Enyedy, I. J. \& Kumaravel, G. Inhibitors of protein-protein interactions: New methodologies to tackle this challenge. Drug Discov. Today, 10, E509-E515 (2013).

11. Arkin, M. Protein-protein interactions and cancer: small molecules going in for the kill. Curr. Opin. Chem Biol. 9, 317- 324 (2005)

This is an early influential review with a focus on the disruption of cancer PPIs; the review highlights with the handful of examples that were known at the time.
12. Villoutreix, B. O., Labbe, C. M., Lagorce, D. Laconde, G. \& Sperandio, O. A leap into the chemical space of protein-protein interaction inhibitors. Curr. Pharm. Des. 18, 4648-4667 (2012). This is an interesting commentary on the properties of compounds that target proteinprotein interactions.

13. Gao, M. \& Skolnick, J. The distribution of ligand binding pockets around protein-protein interfaces suggests a general mechanism for pocket formation Proc. Natl Acad. Sci. USA 109, 3784-3789 (2012)

14. Heeres, J. T. \& Hergenrother, P. J. High-throughput screening for modulators of protein-protein interactions: use of photonic crystal biosensors and complementary technologies. Chem. Soc. Rev. 40, 4398-4410 (2011)

15. Winter, A. et al. Biophysical and computational fragment-based approaches to targeting proteinprotein interactions: applications in structure-guided drug discovery. Q. Rev. Biophys. 45, 383-426 (2012).

16. McFedries, A., Schwaid, A. \& Saghatelian, A. Methods for the elucidation of protein-small molecule interactions. Chem. Biol. 20, 667-673 (2013).

17. Boisclair, M. D., Egan, D. A., Huberman, K. \& Infantino, R. in Cancer Drug Discovery and Development: Anticancer Drug Development Guide: Preclinical Screening, Clinical Trials, and Approval (eds Teicher, B. A. \& Andrews, P. A.) 23-39 (Humana Press Inc., 2004).

18. Pereira, D. A. \& Williams, J. A. Origin and evolution of high throughput screening. Br. J. Pharmacol. 152 53-61 (2007)

19. Baell, J. B. \& Holloway, G. A. New substructure filters for removal of pan assay interference compounds (PAINS) from screening libraries and for their exclusion in bioassays. J. Med. Chem. $\mathbf{5 3}$, 2719-2740 (2010).

This important analysis identifies classes of chemistries that are present in many non-specific, promiscuous molecules and provides computationa methods to identify them in screening libraries.

20. Hermann, J. C. et al. Metal impurities cause false positives in high-throughput screening campaigns. ACS Med. Chem. Lett. 4, 197-200 (2013).

21. Zimmermann, G. et al. Small molecule inhibition of the KRAS-PDE $\delta$ interaction impairs oncogenic KRAS signalling. Nature 497, 638-642 (2013).

22. Czabotar, P. E. \& Lessene, G. Bcl-2 family proteins as therapeutic targets. Curr. Pharm. Des. 16 3132-3148 (2010)

23. Tovar, C. et al. MDM2 small-molecule antagonist RG7112 activates p53 signaling and regresses human tumors in preclinical cancer models. Cancer Res. 73. 2587-2597 (2013)
24. Petros, A. M. et al. Discovery of a potent inhibitor of the antiapoptotic protein Bcl-xL from NMR and parallel synthesis. J. Med. Chem. 49, 656-663 (2006)

25. Qian, J. et al. Discovery of novel inhibitors of Bcl-xL using multiple high-throughput screening platforms Anal. Biochem. 328, 131-138 (2004).

26. Real, P. J. et al. Breast cancer cells can evade apoptosis-mediated selective killing by a novel small molecule inhibitor of $\mathrm{Bcl}-2$. Cancer Res. 64 7947-7953 (2004).

27. Vassilev, L. T. et al. In vivo activation of the p53 pathway by small-molecule antagonists of MDM2. Science 303, 844-848 (2004).

28. Carry, J. C. \& Garcia-Echeverria, C. Inhibitors of the p53/hdm2 protein-protein interaction-path to the clinic. Bioorg. Med. Chem. Lett. 23, 2480-2485 (2013).

29. Vu, B et al. Discovery of RG7112: a small-molecule MDM2 inhibitor in clinical development. ACS Med. Chem. Lett. 4, 466-469 (2013).

30. Ding, Q. et al. Discovery of RG7388, a potent and selective p53-MDM2 inhibitor in clinical development J. Med. Chem. 56, 5979-5983 (2013).

31. Dos-Santos, O. et al. 1017 human dedifferentiated liposarcomas growth inhibition by SAR299155, a potent and selective disruptor of the MDM2-p53 interaction. Eur. J. Cancer 48, S245-S246 (2012).

32. Grasberger, B. L. et al. Discovery and cocrystal structure of benzodiazepinedione HDM2 antagonists that activate p53 in cells. J. Med. Chem. 48 , 909-912 (2005)

33. Kussie, P. H. et al. Structure of the MDM2 oncoprotein bound to the p53 tumor suppressor transactivation domain. Science 274, 948-953 (1996).

34. Milroy, L. G., Brunsveld, L. \& Ottmann, C. Stabilization and inhibition of protein-protein interactions: the 14-3-3 case study. ACS Chem. Biol. 8, 27-35 (2013).

35. Rose, R. et al. Identification and structure of smallmolecule stabilizers of 14-3-3 protein-protein interactions. Angew. Chem. Int. Ed. Engl. 49 , 4129-4132 (2010)

36. Zhao, J et al. Discovery and structura characterization of a small molecule 14-3-3 proteinprotein interaction inhibitor. Proc. Natl Acad. Sci. USA 108, 16212-16216 (2011)

37. Thornberry, N. A. \& Lazebnik, Y. Caspases: enemies within. Science 281, 1312-1316 (1998).

38. Schimmer, A. D. et al. Small-molecule antagonists of apoptosis suppressor XIAP exhibit broad antitumor activity. Cancer Cell 5, 25-35 (2004).

39. Liu, Z. et al. Structural basis for binding of Smac/ DIABLO to the XIAP BIR3 domain. Nature 408 1004-1008 (2000). 
40. Oost, T. K. et al. Discovery of potent antagonists of the antiapoptotic protein XIAP for the treatment of cancer. J. Med. Chem. 47, 4417-4426 (2004).

41. Shi, A. et al. Structural insights into inhibition of the bivalent menin-MLL interaction by small molecules in leukemia. Blood 120, 4461-4469 (2012).

42. Grembecka, J. et al. Menin-MLL inhibitors reverse oncogenic activity of MLL fusion proteins in leukemia. Nature Chem. Biol. 8, 277-284 (2012).

43. Yuriev, E. \& Ramsland, P. A. Latest developments in molecular docking: 2010-2011 in review. J. Mol. Recognit. 26, 215-239 (2013). This is a comprehensive review on the latest docking software, docking methods and scoring techniques used for in silico screening.

44. Froufe, H. J., Abreu, R. M. \& Ferreira, I. C. Virtual screening of low molecular weight mushrooms compounds as potential Mdm2 inhibitors. J. Enzyme Inhib. Med. Chem. 28, 569-575 (2013).

45. Khanna, M. et al. Targeting multiple conformations leads to small molecule inhibitors of the uPAR.uPA protein-protein interaction that block cancer cell invasion. ACS Chem. Biol. 6, 1232-1243 (2011). The plastic nature of protein-protein interfaces and the availability of cheap computational power have led to ensembles of protein conformations being used in virtual screens rather than a single rigid protein model; this article is an excellent example of the multiple protein conformer strategy.

46. Villoutreix, B. O. et al. In silico-in vitro screening of protein-protein interactions: towards the next generation of therapeutics. Curr. Pharm. Biotechnol. 9, 103-122 (2008).

47. Bowman, A. L., Nikolovska-Coleska, Z., Zhong, H., Wang, S. \& Carlson, H. A. Small molecule inhibitors of the MDM2-p53 interaction discovered by ensemblebased receptor models. J. Am. Chem. Soc. 129, 12809-12814 (2007)

48. Nikolovska-Coleska, Z. et al. Discovery of embelin as a cell-permeable, small-molecular weight inhibitor of XIAP through structure-based computational screening of a traditional herbal medicine three-dimensional structure database. J. Med. Chem. 47, 2430-2440 (2004).

49. Enyedy, I. J. et al. Discovery of small-molecule inhibitors of $\mathrm{Bcl}-2$ through structure-based computer screening. J. Med. Chem. 44, 4313-4324 (2001).

50. Ivanov, A. A., Khuri, F. R. \& Fu, H. Targeting proteinprotein interactions as an anticancer strategy. Trends Pharmacol. Sci. 34, 393-400 (2013).

51. Ewing, T. J., Makino, S., Skillman, A. G. \& Kuntz, I. D. DOCK. 4.0: search strategies for automated molecular docking of flexible molecule databases. J. Comput. Aided Mol. Des. 15, 411-428 (2001)

52. Bajwa, N., Liao, C. \& Nikolovska-Coleska, Z. Inhibitors of the anti-apoptotic $\mathrm{Bcl}-2$ proteins: a patent review. Expert Opin. Ther. Pat. 22, 37-55 (2012).

53. Boonstra, M. C. et al. Clinical applications of the urokinase receptor (UPAR) for cancer patients. Curr. Pharm. Des. 17, 1890-1910 (2011)

54. Morris, G. M. et al. AutoDock4 and AutoDockTools4: Automated docking with selective receptor flexibility. J. Comput. Chem. 30, 2785-2791 (2009)

55. Reddy, T. R., Li, C., Fischer, P. M. \& Dekker, L. V. Threedimensional pharmacophore design and biochemical screening identifies substituted 1,2,4-triazoles as inhibitors of the annexin A2-S100A 10 protein interaction. ChemMedChem. 7, 1435-1446 (2012). This is a prime example of the protein-based pharmacophore VS approach.

56. Corradi, V. et al. Computational techniques are valuable tools for the discovery of protein-protein interaction inhibitors: the 14-3-3sigma case. Bioorg Med. Chem. Lett. 21, 6867-6871 (2011)

57. Fry, D. et al. Design of libraries targeting protein-protein interfaces. ChemMedChem. 8, 726-732 (2013).

58. Koes, D. et al. Enabling large-scale design, synthesis and validation of small molecule protein-protein antagonists. PLOS ONE 7, e32839 (2012).

59. Sakkiah, S., Thangapandian, S., John, S. \& Lee, K. W. Pharmacophore based virtual screening, molecular docking studies to design potent heat shock protein 90 inhibitors. Eur. J. Med. Chem. 46, 2937-2947 (2011).

60. Phipps, K. D., Surette, A. P., O'Connell, P. A. \& Waisman, D. M. Plasminogen receptor S100A10 is essential for the migration of tumor-promoting macrophages into tumor sites. Cancer Res. 71, 6676-6683 (2011).

61. Takahashi, S. et al. Cloning and identification of annexin II as an autocrine/paracrine factor that increases osteoclast formation and bone resorption. J. Biol. Chem. 269, 28696-28701 (1994).
62. Shang, J. et al. S100A10 as a novel biomarker in colorectal cancer. Tumour Biol. 34, 3785-3790 (2013).

63. Jones, G., Willett, P., Glen, R. C., Leach, A. R. \& Taylor, R. Development and validation of a genetic algorithm for flexible docking. J. Mol. Biol. 267, 727-748 (1997)

64. Mustata, G. et al. Discovery of novel Myc-Max heterodimer disruptors with a three-dimensional pharmacophore model. J. Med. Chem. 52, 1247-1250 (2009).

65. Chiang, Y. K. et al. Generation of ligand-based pharmacophore model and virtual screening for identification of novel tubulin inhibitors with potent anticancer activity. J. Med. Chem. 52, 4221-4233 (2009).

This article clearly shows the use of a compound-based pharmacophore to carry out a virtual screen of compound libraries.

66. Seifert, M. H. J., Wolf, K. \& Vitt, D. Virtual highthroughput in silico screening. BIOSILICO 1, 143-149 (2003).

67. Hajduk, P. J. \& Greer, J. A decade of fragment-based drug design: strategic advances and lessons learned. Nature Rev. Drug Discov. 6, 211-219 (2007).

68. Sun, C., Petros, A. M. \& Hajduk, P. J. Fragment-based lead discovery: challenges and opportunities. J. Comput. Aided Mol. Des. 25, 607-610 (2011).

69. Hajduk, P. J., Galloway, W. R. \& Spring, D. R. Drug discovery: A question of library design. Nature $\mathbf{4 7 0}$, 42-43 (2011).

70. Scott, D. E., Coyne, A. G., Hudson, S. A. \& Abell, C. Fragment-based approaches in drug discovery and chemical biology. Biochemistry 51, 4990-5003 (2012) This is a well-written update on fragment-based drug discovery.

71. Shuker, S. B., Hajduk, P. J., Meadows, R. P. $\delta$ Fesik, S. W. Discovering high-affinity ligands for proteins SAR by NMR. Science 274, 1531-1534 (1996). This seminal paper introduced the concept of using fragments for drug discovery and the potential of low-affinity hit compounds as the basis for drug development.

72. Hubbard, R. E. Fragment approaches in structurebased drug discovery. J. Synchrotron Radiat. 15, 227-230 (2008).

73. Fischer, M. \& Hubbard, R. E. Fragment-based ligand discovery. Mol. Interv. 9, 22-30 (2009).

74. Erlanson, D. A. Introduction to fragment-based drug discovery. Top. Curr. Chem. 317, 1-32 (2012)

75. Davis, B. J. ¿ Erlanson, D. A. Learning from our mistakes: the 'unknown knowns' in fragment screening. Bioorg. Med. Chem. Lett. 23, 2844-2852 (2013). This well-written review highlights some of the pitfalls and artifacts of fragment screening, as well as how to identify false positives early in the screening process.

76. Erlanson, D. A., McDowell, R. S. \& O'Brien, T. Fragment-based drug discovery. J. Med. Chem. 47, 3463-3482 (2004)

77. Hubbard, R. E. \& Murray, J. B. Experiences in fragment-based lead discovery. Methods Enzymol. 493, 509-531 (2011)

78. Patrone, J. D. et al. Discovery of protein-protein interaction inhibitors of replication protein A. ACS Med. Chem. Lett. 4, 601-605 (2013).

79. Frank, A. O et al. Discovery of a potent inhibitor of replication protein a protein-protein interactions using a fragment-linking approach. J. Med. Chem. 56 9242-9250 (2013).

80. Lepre, C. A. Practical aspects of NMR-based fragment screening. Methods Enzymol 493, 219-239 (2011).

81. Badger, J. Crystallographic fragment screening. Methods Mol. Biol. 841, 161-177 (2012).

82. Chilingaryan, Z., Yin, Z. \& Oakley, A. J. Fragment-based screening by protein crystallography: successes and pitfalls. Int. J. Mol. Sci. 13, 12857-12879 (2012)

83. Danielson, U. H. Fragment library screening and lead characterization using SPR biosensors. Curr. Top. Med. Chem. 9, 1725-1735 (2009).

84. Navratilova, I., Besnard, J. \& Hopkins, A. L. Screening for GPCR ligands using surface plasmon resonance. ACS Med. Chem. Lett. 2, 549-554 (2011).

85. Silvestre, H. L., Blundell, T. L., Abell, C. \& Ciulli, A. Integrated biophysical approach to fragment screening and validation for fragment-based lead discovery. Proc. Natl Acad. Sci. USA 110, 12984-12989 (2013).

86. Bower, J. F. \& Pannifer, A. Using fragment-based technologies to target protein-protein interactions. Curr. Pharm. Des. 18, 4685-4696 (2012).

87. Turnbull, A. P. \& Boyd, S. M. Targeting cancer using fragment based drug discovery. Anticancer Agents Med. Chem. 12, 40-48 (2012).
88. Boettcher, A. et al. Fragment-based screening by biochemical assays: Systematic feasibility studies with trypsin and MMP12. J. Biomol. Screen. 15, 1029-1041 (2010)

89. Tse, C. et al. ABT-263: a potent and orally bioavailable Bcl-2 family inhibitor. Cancer Res. 68, 3421-3428 (2008).

90. Petros, A. M. et al. Discovery of a potent and selective $\mathrm{Bcl}-2$ inhibitor using SAR by NMR. Bioorg. Med. Chem. Lett. 20, 6587-6591 (2010).

91. Lessene, G. et al. Structure-guided design of a selective BCL-XL inhibitor. Nature Chem. Biol. 9 , 390-397 (2013)

92. Aguirre, C. et al. BcL-xL conformational changes upon fragment binding revealed by NMR. PLOS ONE 8 , e64400 (2013).

93. Erlanson, D. A., Wells, J. A. \& Braisted, A. C. Tethering: fragment-based drug discovery. Annu. Rev. Biophys. Biomol. Struct. 33, 199-223 (2004).

94. Arkin, M. R. et al. Binding of small molecules to an adaptive protein-protein interface. Proc. Natl Acad. Sci. USA 100, 1603-1608 (2003).

95. Raimundo, B. C. et al. Integrating fragment assembly and biophysical methods in the chemical advancement of small-molecule antagonists of IL-2: an approach for inhibiting protein-protein interactions. J. Med. Chem. 47, 3111-3130 (2004).

96. Renner, S. et al. Recent trends and observations in the design of high-quality screening collections. Future Med. Chem. 3, 751-766 (2011).

97. Thomas, C. E. \& Will, Y. The impact of assay technology as applied to safety assessment in reducing compound attrition in drug discovery. Expert Opin. Drug Discov. 7, 109-122 (2012).

98. Makley, L. N. \& Gestwicki, J. E. Expanding the number of 'druggable' targets: non-enzymes and proteinprotein interactions. Chem. Biol. Drug Des. 81, 22-32 (2013)

99. Barker, A., Kettle, J. G., Nowak, T. \& Pease, J. E. Expanding medicinal chemistry space. Drug Discov. Today 18, 298-304 (2013)

100. Waldmann, T. A. Immunotherapy: past, present and future. Nature Med. 9, 269-277 (2003).

101. Dimitrov, D. S. Therapeutic proteins. Methods Mol. Biol. 899, 1-26 (2012)

102. De Souza, E. B., Cload, S. T., Pendergrast, S. P. \& Sah, D. W. Y. Novel therapeutic modalities to address nondrugable protein interaction targets. Neuropsychopharmacology 34, 142-158 (2009).

103. Ratnaparkhi, M. P., Chaudhari, S. P. \& Pandya, V. A Peptides and proteins in pharmaceuticals. Int. J. Curr. Pharm. Res. 3, 1-9 (2011)

104. Miller, M. J., Foy, K. C. \& Kaumaya, P. T. P. Cancer immunotherapy: present status, future perspective and a new paradigm of peptide immunotherapeutics. Disc. Med. 15, 166-176 (2013).

105. Tomlinson, I. M. Next-generation protein drugs. Nature Biotech. 22, 521-522 (2004).

106. Nelson, A. L., Dhimolea, E. \& Reichert, J. M. Development trends for human monoclonal antibody therapeutics. Nature Rev. Drug Discov. 9, 767-774 (2010)

107. Flego, M., Ascione, A., Cianfriglia, M. \& Vella, S. Clinical development of monoclonal antibody-based drugs in HIV and HCV diseases. BMC Med. 11, 4 (2013).

108. Otvos, L. Jr Peptide-based drug design: here and now. Methods Mol. Biol. 494, 1-8 (2008).

109. Roy, S. et al. Peptide based molecules as protein-protein interaction inhibitors: tools for chemical genetics and therapy. Curr. Chem. Biol. 6, 145-163 (2012).

110. Souroujon, M. C. \& Mochly-Rosen, D. Peptide modulators of protein-protein interactions in intracellular signaling. Nature Biotech. 16, 919-924 (1998).

111. Tan, T. T. \& White, E. Therapeutic targeting of death pathways in cancer: mechanisms for activating cell death in cancer cells. Adv. Exp. Med. Biol. 615, 81-104 (2008)

112. Sleebs, B. E. et al. Discovery of potent and selective benzothiazole hydrazone inhibitors of $\mathrm{Bcl}-\mathrm{XL}$. J. Med. Chem. 56, 5514-5540 (2013)

113. Muppidi, A. et al. Rational design of proteolytically stable, cell-permeable peptide-based selective $\mathrm{Mcl}-1$ inhibitors. J. Am. Chem. Soc. 134, 14734-14737 (2012) This is a good example of peptide stabilization through crosslinking and rational design.

114. Paschke, M. Phage display systems and their applications. Appl. Microbiol. Biotechnol. 70, 2-11 (2006). 
115. Fischer, P. M. \& Lane, D. P. Small-molecule inhibitors of the p53 suppressor HDM2: have protein-protein interactions come of age as drug targets? Trends Pharmacol. Sci. 25, 343-346 (2004).

116. Garcia-Echeverria, C., Chene, P., Blommers, M. J. \& Furet, P. Discovery of potent antagonists of the interaction between human double minute 2 and tumor suppressor p53. J. Med. Chem. 43, 3205-3208 (2000).

This is a good example of how molecular modelling, biology, crystallography and chemistry were used to develop peptide agonists.

117. Mehan, M. R. et al. Highly multiplexed proteomic platform for biomarker discovery, diagnostics, and therapeutics. Adv. Exp. Med. Biol. 735, 283-300 (2013).

118. Zhu, G. et al. Nucleic acid aptamers: an emerging frontier in cancer therapy. Chem. Commun. (Camb.) 48, 10472-10480 (2012).

119. Chen, C. H., Chernis, G. A., Hoang, V. Q. \& Landgraf, R. Inhibition of heregulin signaling by an aptamer that preferentially binds to the oligomeric form of human epidermal growth factor receptor-3. Proc. Natl Acad. Sci. USA 100, 9226-9231 (2003).

120. Dastjerdi, K., Tabar, G. H., Dehghani, H. \& Haghparast, A. Generation of an enriched pool of DNA aptamers for an HER2-overexpressing cell line selected by Cell, SELEX. Biotechnol. Appl. Biochem. 58, 226-230 (2011)

121. Esposito, C. L. et al. A neutralizing RNA aptamer against EGFR causes selective apoptotic cell death. PLOS ONE 6, e24071 (2011).

122. Kim, M. Y. \& Jeong, S. In vitro selection of RNA aptamer and specific targeting of ErbB2 in breast cancer cells. Nucleic Acid. Ther. 21, 173-178 (2011).

123. Mahlknecht, G. et al. Aptamer to ErbB-2/HER2 enhances degradation of the target and inhibits tumorigenic growth. Proc. Natl Acad. Sci. USA 110 8170-8175 (2013)

124. Dassie, J. P. et al. Systemic administration of optimized aptamer-siRNA chimeras promotes regression of PSMA-expressing tumors. Nature Biotech. 27, 839-849 (2009).

125. Majumder, P., Gomes, K. N. \& Ulrich, H. Aptamers: from bench side research towards patented molecules with therapeutic applications. Expert Opin. Ther. Patents 19, 1603-1613 (2009).

126. Din, O. S. \& Woll, P. J. Treatment of gastrointestinal stromal tumor: focus on imatinib mesylate. Ther Clin. Risk Manag. 4, 149-162 (2008).

127. McMillan, K. et al. Allosteric inhibitors of inducible nitric oxide synthase dimerization discovered via combinatorial chemistry. Proc. Natl Acad. Sci. USA 97, 1506-1511 (2000)

128. Eyrisch, S. \& Helms, V. Transient pockets on protein surfaces involved in protein-protein interaction. J. Med. Chem. 50, 3457-3464 (2007).

129. Lo Conte, L., Chothia, C. \& Janin, J. The atomic structure of protein-protein recognition sites. J. Mol. Biol. 285, 2177-2198 (1999).

130. Clackson, T. \& Wells, J. A. A hot spot of binding energy in a hormone-receptor interface. Science $\mathbf{2 6 7}$, 383-386 (1995)

This is the paper that introduced the concept of the hot spot in protein-protein interfaces.

131. DeLano, W. L., Ultsch, M. H., de Vos, A. M. \& Wells, J. A. Convergent solutions to binding at a protein-protein interface. Science 287, 1279-1283 (2000).

132. Bogan, A. A. \& Thorn, K. S. Anatomy of hot spots in protein interfaces. J. Mol. Biol. 280, 1-9 (1998).

133. de Vos, A. M., Ultsch, M. \& Kossiakoff, A. A. Human growth hormone and extracellular domain of its receptor: crystal structure of the complex. Science 255, 306-312 (1992)

134. Clackson, T., Ultsch, M. H., Wells, J. A. \& de Vos, A. M. Structural and functional analysis of the $1: 1$ growth hormone:receptor complex reveals the molecular basis for receptor affinity. J. Mol. Biol. 277 1111-1128 (1998)

135. Manion, M. K. et al. Bcl-XL mutations suppress cellular sensitivity to antimycin A. J. Biol. Chem. 279 2159-2165 (2004).
136. Czabotar, P. E. et al. Mutation to Bax beyond the BH3 domain disrupts interactions with pro-survival proteins and promotes apoptosis. J. Biol. Chem. 286, 7123-7131 (2011).

137. Okamoto, T. et al. Stabilizing the pro-apoptotic BimBH3 helix (BimSAHB) does not necessarily enhance affinity or biological activity. ACS Chem. Biol. 8, 297-302 (2013)

138. Lee, E. F. et al. Crystal structure of ABT-737 complexed with $\mathrm{Bcl}-\mathrm{xL}$ : implications for selectivity of antagonists of the $\mathrm{BCl}-2$ family. Cell Death Differ 14, 1711-1713 (2007).

139. Rickert, M., Wang, X., Boulanger, M. J. Goriatcheva, N. \& Garcia, K. C. The structure of interleukin-2 complexed with its $\alpha$ receptor. Science 308, 1477-1480 (2005).

140. Thanos, C. D., DeLano, W. L. \& Wells, J. A. Hot-spot mimicry of a cytokine receptor by a small molecule. Proc. Natl Acad. Sci. USA 103, 15422-15427 (2006).

141. Thanos, C. D., Randal, M. \& Wells, J. A. Potent smallmolecule binding to a dynamic hot spot on IL-2. J. Am Chem. Soc. 125, 15280-15281 (2003). This is the key reference in the development of the technique of tethered fragment-based design and its application to the production of PPI modulators.

142. Glanzer, J. G. et al. A small molecule directly inhibits the p53 transactivation domain from binding to replication protein A. Nucleic Acids Res. 41 2047-2059 (2013).

143. Gang, E. J. et al. Small-molecule inhibition of CBP catenin interactions eliminates drug-resistant clones in acute lymphoblastic leukemia. Oncogene http://dx.doi.org/10.1038/onc.2013.169 (2013).

144. Emami, K. H. et al. A small molecule inhibitor of $\beta$-catenin/CREB-binding protein transcription [corrected]. Proc. Natl Acad. Sci. USA 101, 12682-12687 (2004)

145. Fulda, S. \& Vucic, D. Targeting IAP proteins for therapeutic intervention in cancer. Nature Rev. Drug Discov. 11, 109-124 (2012).

146. Bellmunt, J. et al. Phase III trial of vinflunine plus best supportive care compared with best supportive care alone after a platinum-containing regimen in patients with advanced transitional cell carcinoma of the urothelial tract. J. Clin. Oncol. 27, 4454-4461 (2009)

147. Ngan, V. K. et al. Novel actions of the antitumor drugs vinflunine and vinorelbine on microtubules. Cancer Res. 60, 5045-5051 (2000)

148. Towle, M. J. et al. In vitro and in vivo anticancer activities of synthetic macrocyclic ketone analogues of halichondrin B. Cancer Res. 61, 1013-1021 (2001)

149. Morris, P. G. Advances in therapy: eribulin improves survival for metastatic breast cancer. Anticancer Drugs 21, 885-889 (2010).

150. Conlin, A., Fornier, M., Hudis, C., Kar, S. \& Kirkpatrick, P. Ixabepilone. Nature Rev. Drug Discov. 6, 953-954 (2007)

151. Lee, F. Y et al. BMS-247550: a novel epothilone analog with a mode of action similar to paclitaxel but possessing superior antitumor efficacy. Clin. Cancer Res. 7, 1429-1437 (2001)

152. Weisberg, E. et al. Smac mimetics: implications for enhancement of targeted therapies in leukemia. Leukemia 24, 2100-2109 (2010).

153. Houghton, P. J. et al. Initial testing (stage 1) of LCL161, a SMAC mimetic, by the Pediatric Preclinical Testing Program. Pediatr. Blood Cancer 58, 636-639 (2012).

154. Gandhi, L. et al. Phase I study of Navitoclax (ABT-263), a novel Bcl-2 family inhibitor, in patients with small-cell lung cancer and other solid tumors. J. Clin. Oncol. 29, 909-916 (2011).

155. Hwang J J et al. Phase I dose finding studies of obatoclax (GX15-070), a small molecule pan-BCL-2 family antagonist, in patients with advanced solid tumors or lymphoma. Clin. Cancer Res. 16 4038-4045 (2010).

156. O'Brien, S. M. et al. Phase I study of obatoclax mesylate (GX15-070), a small molecule pan-Bcl-2 family antagonist, in patients with advanced chronic lymphocytic leukemia. Blood 113, 299-305 (2009)
157. Schimmer A. D et al. A phase I study of the pan bcl-2 family inhibitor obatoclax mesylate in patients with advanced hematologic malignancies. Clin. Cancer Res. 14, 8295-8301 (2008)

158. Gore, M. E., Harrison, M. L. \& Montes, A. New drug therapies for advanced renal cell carcinoma. Expert Rev. Anticancer Ther. 7, 57-71 (2007).

159. Rini, B., Kar, S. \& Kirkpatrick, P. Temsirolimus. Nat. Rev. Drug Discov. 6, 599-600 (2007)

160. Heist, R. S. et al. Phase I/II study of AT-101 with topotecan in relapsed and refractory small cell lung cancer. J. Thorac. Oncol. 5, 1637-1643 (2010).

161. Liu, G. et al. An open-label, multicenter, phase I/II study of single-agent AT-101 in men with castrateresistant prostate cancer. Clin. Cancer Res. 15. 3172-3176 (2009).

162. Mita, A. C. et al. Phase I and pharmacokinetic study of XRP6258 (RPR 116258A), a novel taxane administered as a 1-hour infusion every 3 weeks in patients with advanced solid tumors. Clin. Cancer Res. 15, 723-730 (2009)

\section{Acknowledgements}

This work was supported by a capital grant from the Australian Cancer Research Foundation and infrastructure funding from the Victorian Government (Australia) Operational Infrastructure Support Scheme to St Vincent's Institute, Fitzroy, Victoria, Australia. M.W.P. is a National Health and Medical Research Council of Australia Research Fellow. J.K.H. is a joint Cure Cancer/Leukaemia Foundation Post-Doctoral Fellow.

\section{Competing interests statement}

The authors declare competing interests: see Web version for details.

\section{DATABASES}

The Cancer Genome Atlas: http://cancergenome.nih.gov/ International Cancer Genome Consortium: http://icgc.org/ ClinicalTrials.gov: http://ClinicalTrials.gov

National Cancer Institute DIS 3D database: http://dtp.nci.nih.gov/docs/3d database/dis3d.html Protein Data Bank: http://www.rcsb.org/pdb/home/home.do

FURTHER INFORMATION

2P2ldb: http://2p2idb.cnrs-mrs.fr/

Accelrys: www.accelrys.com

ANCHOR: http://structure.pitt.edu/anchor/

Click2Drug: http://www.click2drug.org/

Developmental Therapeutics Program, $\mathrm{NCl} / \mathrm{NIH}$

http://dtp.nci.nih.gov/index.htm

Dictionary of Marine Products: http://dmnp.chemnetbase.com

Dictionary of Natural Products: http://dnp.chemnetbase.com

DrugBank: http://www.drugbank.ca/

FAF-Drugs2 server:

http://bioserv.rpbs.univ-paris-diderot.fr/FAF-Drugs/

FDA Drug-related Databases:

http://www.fda.gov/Drugs/default.htm

Human Cancer Protein Interaction Network (HCPIN):

http://www.nesg.org:9090/HCPIN/index.jsp

iPPI-DB: http://www.ippidb.cdithem.fr/

National Cancer Institute (NIH, USA): http://cancer.gov/

NCGC Pharmaceutical Collection (NPC):

http://tripod.nih.gov/npc/

PPI Network: http://ppi-net.org/

PrePPI: http://bhapp.c2b2.columbia.edu/PrePPI/

Protein-Protein Interactions: http://bip.weizmann.ac.il/

toolbox/structure/protein-protein.htm\#db2

Schrödinger: http://www.schrodinger.com

The MIPS Mammalian Protein-Protein Interaction Database:

ttp://mips.helmholtz-muenchen.de/proj/ppi/

The Protein Interaction Network Analysis (PINA)

http://cbg.garvan.unsw.edu.au/pina/

TIMBAL: http://mordred.bioc.cam.ac.uk/timbal/

Virtual Ligand Screening in 3D.com:

http://www.vls3d.com/links.html

Wiki-Pi: http://severus.dbmi.pitt.edu/wiki-pi/

SUPPLEMENTARY INFORMATION

See online article: $\underline{\mathrm{S}}$ (table) $\mid \underline{\mathrm{S} 2}$ (table) $\mid \underline{\mathrm{S}}$ (table) $\mid \underline{\mathrm{S}} 4$ (table)

ALL LINKS ARE ACTIVE IN THE ONLINE PDF 